\title{
ASSESSING POTENTIAL FUTURE ENVIRONMENTAL LEGISLATIVE, REGULATORY, AND JUDICIAL EVENTS
}

\author{
Bruce Tonn \\ Martin Schweitzer \\ National Center for Environmental Decision-making Research \\ Oak Ridge National Laboratory \\ P.O. Box 2008 \\ Oak Ridge, TN 37831-6207 \\ E-mail: bet@ornl.gov \\ Carl Wagner \\ University of Tennessee-Knoxville \\ Gina Godfrey \\ National Center for Environmental Decision-making Research
}

Donald G. MacGregor

MacGregor-Bates, Inc.

This submitted manuscript has been authored by a contractor of the US, Government under contract No DE AC05 960R22464 Accordingly, the Us, Government retains a nonexclusive, royalty free license to publish or reproduce the published tom of this contribution, or allow others to do so, for US Government purposes:

March 1998

Prepared by the

OAK RIDGE NATIONAL LABORATORY

Oak Ridge, Tennessee 37831

managed by

LOCKHEED MARTIN ENERGY RESEARCH CORPORATION

for the

U.S. DEPARTMENT OF ENERGY

under contract DE-AC05-96OR22464

* This research was supported by the Environmental Management Program of the Tennessee Valley Authority and by the National Science Foundation under grant SBR-9513010. 


\section{DISCLAIMER}

This report was prepared as an account of work sponsored by an agency of the United States Government. Neither the United States Government nor any agency thereof, nor any of their employees, makes any warranty, express or implied, or assumes any legal liability or responsibility for the accuracy, completeness, or usefulness of any information, apparatus, product, or process disclosed, or represents that its use would not infringe privately owned rights. Reference herein to any specific commercial product, process, or service by trade name, trademark, manufacturer, or otherwise does not necessarily constitute or imply its endorsement, recommendation, or favoring by the United States Government or any agency thereof. The views and opinions of authors expressed herein do not necessarily state or reflect those of the United States Government or any agency thereof. 


\section{DISCLAIMER}

Portions of this document may be illegible electronic image products. Images are produced from the best available original document. 


\section{TABLE OF CONTENTS}

EXECUTIVE SUMMARY $\ldots \ldots \ldots \ldots \ldots \ldots \ldots \ldots \ldots \ldots \ldots \ldots \ldots \ldots$ ix

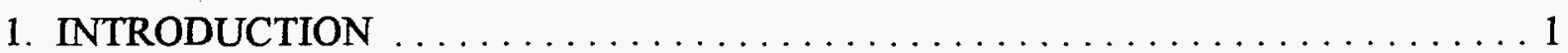

2. REVIEW OF EXISTING ASSESSMENT PROCEDURES $\ldots \ldots \ldots \ldots \ldots \ldots$

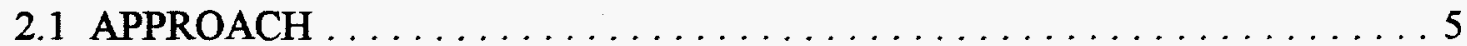

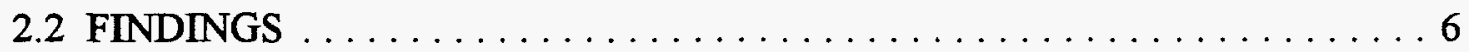

2.3 OBSERVATIONS $\ldots \ldots \ldots \ldots \ldots \ldots \ldots \ldots \ldots \ldots \ldots \ldots \ldots \ldots \ldots \ldots \ldots \ldots$

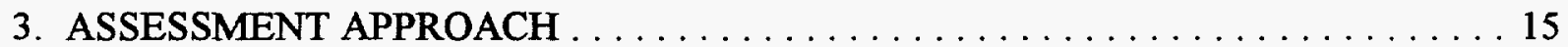

3.1 ISSUES, EVENTS AND SCENARIOS: KEY ASSESSMENT CONCEPTS

3.2 TRACKING EVENTS OVER TIME: DATABASE ELEMENTS $\ldots \ldots \ldots 20$

3.3 UNCERTAINTY REPRESENTATION METHODS $\ldots \ldots \ldots \ldots \ldots \ldots 23$

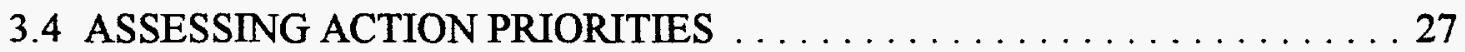

3.5 REPORTING ASSESSMENT RESULTS $\ldots \ldots \ldots \ldots \ldots \ldots \ldots \ldots \ldots$

3.6 ASSESSMENT APPROACH STEPS $\ldots \ldots \ldots \ldots \ldots \ldots \ldots \ldots \ldots$

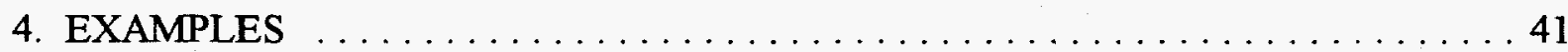

4.1 AIR QUALITY . . . . . . . . . . . . . . . . . . . . . 42

4.2 WATER RESOURCES $\ldots \ldots \ldots \ldots \ldots \ldots \ldots \ldots \ldots \ldots \ldots \ldots$

5. IMPLEMENTATION ISSUES AND CONCLUSIONS $\ldots \ldots \ldots \ldots \ldots \ldots \ldots \ldots$

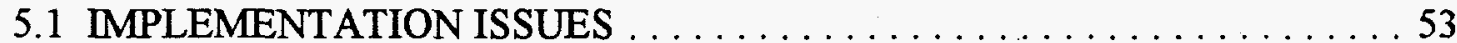

5.2 POTENTIAL FUTURE IMPROVEMENTS TO ASSESSMENT

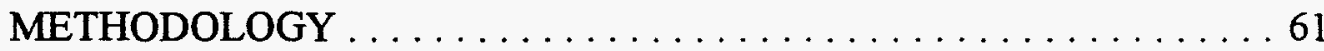

5.3 CONCLUDING THOUGHTS $\ldots \ldots \ldots \ldots \ldots \ldots \ldots \ldots \ldots \ldots \ldots \ldots \ldots \ldots$

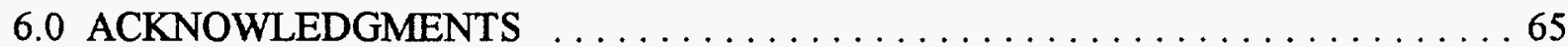

APPENDIX A. EVENT TRACKING DATABASE DEFINITIONS $\ldots \ldots \ldots \ldots$ A - 1

APPENDIX B. MATHEMATICAL NOTES $\ldots \ldots \ldots \ldots \ldots \ldots \ldots \ldots \ldots \ldots$ B -1 


\section{LIST OF FIGURES}

Figure 1. Schematic representation of major assessment methodology concepts $\ldots \ldots 17$

Figure 2. Example relationships between drivers and events $\ldots \ldots \ldots \ldots \ldots \ldots$

Figure 3. Example probability of event occurring stories $\ldots \ldots \ldots \ldots \ldots \ldots \ldots \ldots$

Figure 4. Generic measures of action urgency $\ldots \ldots \ldots \ldots \ldots \ldots \ldots \ldots \ldots \ldots \ldots$

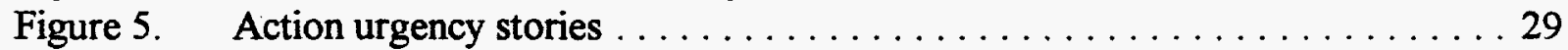

Figure 6. Tracking status and action priority of potential future environmental regulatory

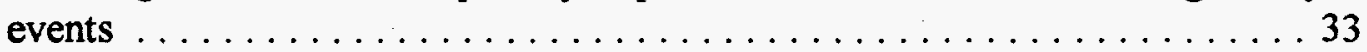

Figure 7. Current scenarios for a potential future environment regulatory event $e_{i} \ldots \ldots 35$

Figure 8. Tracking status and consequences of potential future environmental regulatory

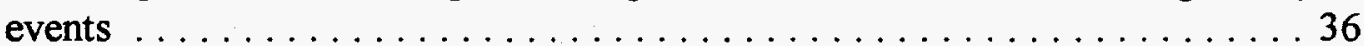

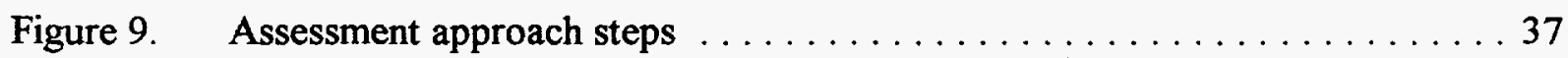




\section{EXECUTIVE SUMMARY}

This report describes a methodology to proactively and methodically assess future potential environmental legislative, regulatory, and judicial events. This is an important endeavor because new, revised, and reauthorized legislation, proposed and final regulations, and outcomes of judicial proceedings have the potential to impose new actions, directions, and costs on many organizations in the United States (related to capital investments, operating approaches, and research and development) and to affect the quality of life. The electric power industry is particularly impacted by environmental regulatory events (the term 'regulatory' is used to cover all the types of legal events listed above), as the generation, transmission, and distribution of electricity affect air and water quality, require disposal of solid, hazardous, and radioactive wastes, and at times, impact wetlands and endangered species. Numerous potential regulatory events, such as reauthorization of the Clean Water Act and new regulations associated with global climate change, can greatly affect the power industry. Organizations poised to respond proactively to such events will improve their competitive positions, reduce their costs in the long-term, and improve their public images.

Many large organizations already track potential future environmental regulatory events. Nine companies were interviewed (four electric utilities, five other major companies). All these companies engage in information gathering activities, mostly by participating in professional and trade association activities, engaging in discussions with key legislators and regulators, and monitoring appropriate publications. Some companies have formal staff responsible for these activities, others employ more informal arrangements. Only four of the nine companies produce formal regulatory outlooks. Information is disseminated through seminars, presentations, and written materials. In general, the companies' approaches can be greatly improved. In only one instance did the time frame of assessment extend past two years. Probabilities, if used, are used typically in a very simple fashion. None of the companies' staff interviewed employs a special conceptual framework for tracking potential future 
environmental regulatory events. Methods do not appear to be employed to assist these companies in prioritizing proactive behaviors in response to potential events.

The assessment methodology presented herein is designed to guide effective and repeatable tracking of environmental regulatory events and to indicate priorities related to potential actions in response to the potential events. The assessment methodology has five components. The first component relates to defining what should be tracked. Semantic definitions are given to the concepts of issues, events, scenarios and drivers. Issues are matters of importance to the organization. An event is something which occurs and comes into being. Scenarios represent potential outcomes, or stories, associated with events (only one scenario can become true). Drivers influence events to occur or not to occur. An organization needs to track event drivers and events first and foremost, in light of important issues. There is also a need to understand the range of scenarios and drivers.

The second component relates to how to track events. Events follow a fairly standard path for coming into being. The path has four stops (or categories): over the horizon - events here have a glimmer of possibility; on the horizon - events here have a stronger chance of occurring and are receiving increased attention; on the screen - events here are receiving much attention from legislators, regulators and others; and on the agenda - decisions about these events may be on the calender for decision making bodies. An organization needs to implement intelligence gathering approaches to discern in which category a potential future environmental regulatory event resides and to detect changes in the event's status.

The third component relates to uncertainty about the occurrence of events and which scenarios will become true if the events occur. With respect to both challenges, lower and upper probabilities are employed to provide to analysts charged with tracking the events the most flexibility for expressing large uncertainties about the likelihood of events. The lower and upper probabilities associated with events are captured in a series of stories which provide a framework for analysts to understand how an event may play out into the future. The stories 
capture conditional probabilities (i.e., if the event has not occurred by this point in time, what is the probability that the event will occur during the next time period). Using this approach, one can define several stories, such as: inevitability - where the lower and upper probabilities converge at some point in the future; anything goes - where lower and upper probabilities diverge in the future from a low point in the near term; and missed opportunity - where the lower and upper probabilities peak at some point in the future and then decline after the opportunity is missed (e.g., Congress adjourns). Lower and upper probabilities are also assessed for scenarios.

The fourth component relates to assessing action priorities. The concept of action urgency is introduced and is defined as the importance to the organization (or any department within the organization) of taking action of some sort in reference to a potential future environmental regulatory event at different periods of time before the event occurs. In essence, the measure of action urgency captures the strategy one would use to respond to an event if one knew exactly when it would occur. Far into the future, there may be little need to act proactively, so urgency of action may be low or zero. There is usually a preferred lead time for actions to be initiated if one knows when something will happen. At this point in time, urgency of action increases to a maximum. Urgency of action stays at a maximum until the event occurs, or until the event is so imminent that continued, or newly implemented, actions would be fruitless. It must be noted that urgency of action will be different among different departments in the organization. Some departments will have longer lead times than others and some events will be more important to some departments than others. The methodology can accommodate these differences.

Mathematical formulas are provided to calculate lower and upper expected values of action urgency, using the lower and upper cumulative probability functions over the occurrence of the event, which are calculated from the conditional probabilities discussed above. A factor is provided to perform sensitivity analyses on prioritizing events over their expected lower and 
upper action urgencies with different levels of risk aversion (i.e., planning based on upper probabilities or planning based on lower probabilities).

The last component of the assessment methodology pertains to communicating its results to people throughout the organization. Several displays are presented for consideration. The displays are designed to communicate several channels of information using color and appropriate symbols. The displays can be generated by software tied to databases and spreadsheet programs that contain the tracking information.

The report includes two examples of applications of the assessment methodology of importance to the power industry. The events are: EPA implements state by state $\mathrm{NO}_{\mathrm{x}}$ emissions budget (CAA Section 110); and EPA implements new cooling water intake regulations/CWA Section 316 (b). Electric power industry regulatory analysts and media specialists participated in each exercise. Time was spent identifying issues, defining the substantive events, categorizing the events (e.g., on the screen), identifying elements of scenarios, building example scenarios, constructing measures of urgency, listing and evaluating event drivers, and eliciting event lower and upper probabilities. Overall, the exercises were successful. However, important observations were made about how to improve structuring of the problem, eliciting the probabilities and action urgency curves, dealing with disagreements and finding consensus, and institutionalizing the assessment process within an organization.

The initial assessment methodology presented herein can be made even more sophisticated. Mathematical links can be made between magnitudes of consequences and event and scenario probabilities to calculate expected consequences to the organization. Drivers can be tracked and their probabilities elicited. If this is done, then the lower and upper probabilities of events can be calculated based on the lower and upper probabilities of the drivers, instead of directly as is now recommended. These additional enhancements may or may not be beneficial to an organization, given their added time and cost for implementation. Indeed, it probably is not 
possible for an organization to track all potential future environmental regulatory events and their drivers, to imagine all over the horizon events which may make it on the horizon, and to specify all scenario elements and assess potentially thousands of resulting scenarios. The organization will have to circumscribe its efforts because everything cannot be tracked. Time and experience will help to guide an organization on how to best use its resources to assess potential future environmental regulatory events. In some cases, different departments within an organization may want to utilize this common methodology, but concentrate on different issues and events. 


\section{INTRODUCTION}

This report describes a set of methods developed for assessing potential future environmental legislation, regulations, and judicial outcomes, collectively referred to as regulatory events. Environmental protection is an important goal of American society. Over the past several decades, numerous major pieces of legislation have been enacted and thousands of environmental regulations have been promulgated. Examples include federal laws and regulations to improve air and water quality, manage the disposal of solid and hazardous wastes, and protect wetlands and endangered species. New legislation, revision of existing legislation, and proposed and final regulations are in the offing. Additionally, outcomes of judicial proceedings can alter, sometimes substantively, the implementation of laws and regulations and the priorities administrative agencies place on enacting new regulations.

Many potential future environmental regulatory events may pose significant financial and public relations challenges to private sector companies and government institutions alike. An effective organization needs to plan ahead, and to anticipate to the highest degree possible in a very uncertain world what environmental regulatory events may occur in the future and what the impacts of the events could have on the organization. At times, it might be an optimal strategy for an organization to consider and appropriately implement research and development programs, project initiatives, and even major capital investment actions several years before a regulatory event is forecast to occur in order to gain a competitive advantage, to maximize returns on investment streams, and to improve public persona.

A comprehensive and proactive business approach involves tracking regulatory events which seem over the horizon to those which are active items on the political or administrative agenda. Assessing such a range of potential future environmental regulatory events is a daunting challenge. Peering five to ten or more years into the future requires imagination to hypothesize regulatory events which today may have no names nor are being meaningfully 
discussed but could eventually occur and significantly impact the organization. Even events which may occur in the nearer term may be hard to predict. This is because legislative, regulatory and judicial processes often move in an erratic, if not in a seemingly random, fashion. Numerous hard to predict factors, such as accidents, sensational media stories, pronounced environmental events, $R \& D$ results, devastating weather events, and changes in political majorities and power, buffet about the political and regulatory processes. Tracking requires hard work, attention to detail, and a determination to tackle uncertainty.

One industry that has a particular need to track future environmental regulatory events is the electric power industry. The generation, transmission, and distribution of electricity affect air and water quality, require acquisition and/or use of land, require the disposal of solid, hazardous and radioactive wastes, and, at times, impact wetlands, endangered species, and human health. Major pieces of federal legislation, such as the Clean Air Act Amendments of 1990 and its associated regulations, have had substantial financial impacts upon the electric power industry. Global warming is an issue on the horizon which could spawn future environmental regulatory events that could greatly impact the electric power industry. Reauthorization and revisions of several major pieces of environmental law, such as the Clean Water Act, are also on the legislative screen.

Section 2 overviews current approaches being taken by several electric power companies and other large corporations to assess future environmental regulations. While it was found that formal efforts to assess future environmental regulations are still fairly uncommon, efforts in the area are growing as electric companies and other large corporations attempt to implement more proactive strategies to deal with potential future environmental regulatory events. The range of approaches being taken is quite broad. Next generation approaches are needed for issue tracking and priority setting that employ sophisticated and rigorous uncertainty representation and display techniques. 
Section 3 presents a methodical, repeatable approach to assessing potential future environmental regulatory events that addresses the needs expressed above. As outlined in Section 3.1, the approach is based upon three major concepts: issues, events, and scenarios. A special framework for tracking future environmental regulatory events is developed (Section 3.2). Uncertainty representation techniques based on imprecise probabilities (i.e., lower and upper probabilities) are employed to construct stories about "if and when" regulatory events may happen in the future (Section 3.3). A method is developed to assign an action priority to each potential future regulatory event (Section 3.4). Illustrations of how the information can be presented to decision makers are presented (Section 3.5). Lastly, a step-by-step description of how to use the assessment approach is presented (Section 3.6).

Section 4 presents two applications of the methods presented in Section 3 that are of interest to electric power industry companies. One example relates to air quality, specifically to potential EPA regulations limiting $\mathrm{NO}_{\mathrm{x}}$ emissions on a state-by-state basis. A second example relates to water quality, specifically to potential EPA regulations pertaining to water intake by power plants.

Section 5 discusses implementation issues, strengths and weaknesses of the approach developed herein, and concluding observations. Implementation issues are extremely important. The assessment methodology presented below represents a significant new effort for most organizations. How to fit the approach into existing work processes is an important issue. Problems associated with implementing each aspect of the methodology by groups of real regulatory analysts need to be confronted (e.g., how to handle disagreements). Training and leadership issues are also addressed in this section. 


\section{REVIEW OF EXISTING ASSESSMENT PROCEDURES}

The first task of this research project was to document existing procedures used by large organizations to assess potential future environmental regulatory events. Section 2.1 presents the approach taken to assess the state-of-the-art in this area. Section 2.2 presents our findings. Section 2.3 provides our evaluation of the findings and needs for improvements to existing assessment procedures.

\subsection{APPROACH}

The approach taken to describe the current state-of-the-art was to interview people involved in assessing potential future environmental regulatory events in both major electric utilities and other major corporations that are particularly impacted by such regulatory events. Interviews were conducted with four major utilities and five other major corporations. Because in several cases the methods being employed and the fact that they were being employed were viewed as competitive advantages, the identities of the utilities and corporations are not revealed in this report.

The following questions were developed to guide the interview process:

- Do you have a procedure that you use to anticipate, track, and address new environmental issues and regulations?

- If "yes", please describe the basic process and send a written description, if possible.

- How well does the procedure work?

- Are there any issues/regulations that your procedures have failed to anticipate? If so, describe them. 
- Do you use the information you gather to develop a "future regulatory outlook," with probabilities and implications for the company?

- If "yes," describe what a typical "future regulatory outlook" looks like and how this information is disseminated, and send a sample document, if possible.

- If "no," how is the information on future regulations that you collect incorporated into business decisions?

- And how would you ideally do a "future regulatory outlook," assuming unlimited resources?

\subsection{FINDINGS}

The nine companies surveyed employ numerous methods and sources to anticipate new environmental issues and regulatory events. As indicated in Table 1, most of these activities involve talking with people within one's industry and who regulate one's industry, and tracking appropriate publications and professional initiatives.

Input from four companies was garnered on their formal procedures used to track potential future environmental regulatory events. It should be noted that most of these companies involve multiple departments in their tracking of environmental issues and regulations. From Table 2, the approaches differ in their formality, from setting up a formal regulatory services group to establishing more informal teams, and in their relationships to an organization's processes, from a formal tracking staff to internalizing tracking within a performance planning process. 
Table 1: Methods/Sources Used to Anticipate Potential Future Environmental Regulatory Events (number of companies reported in brackets) ${ }^{1}$

\begin{tabular}{|c|c|}
\hline & 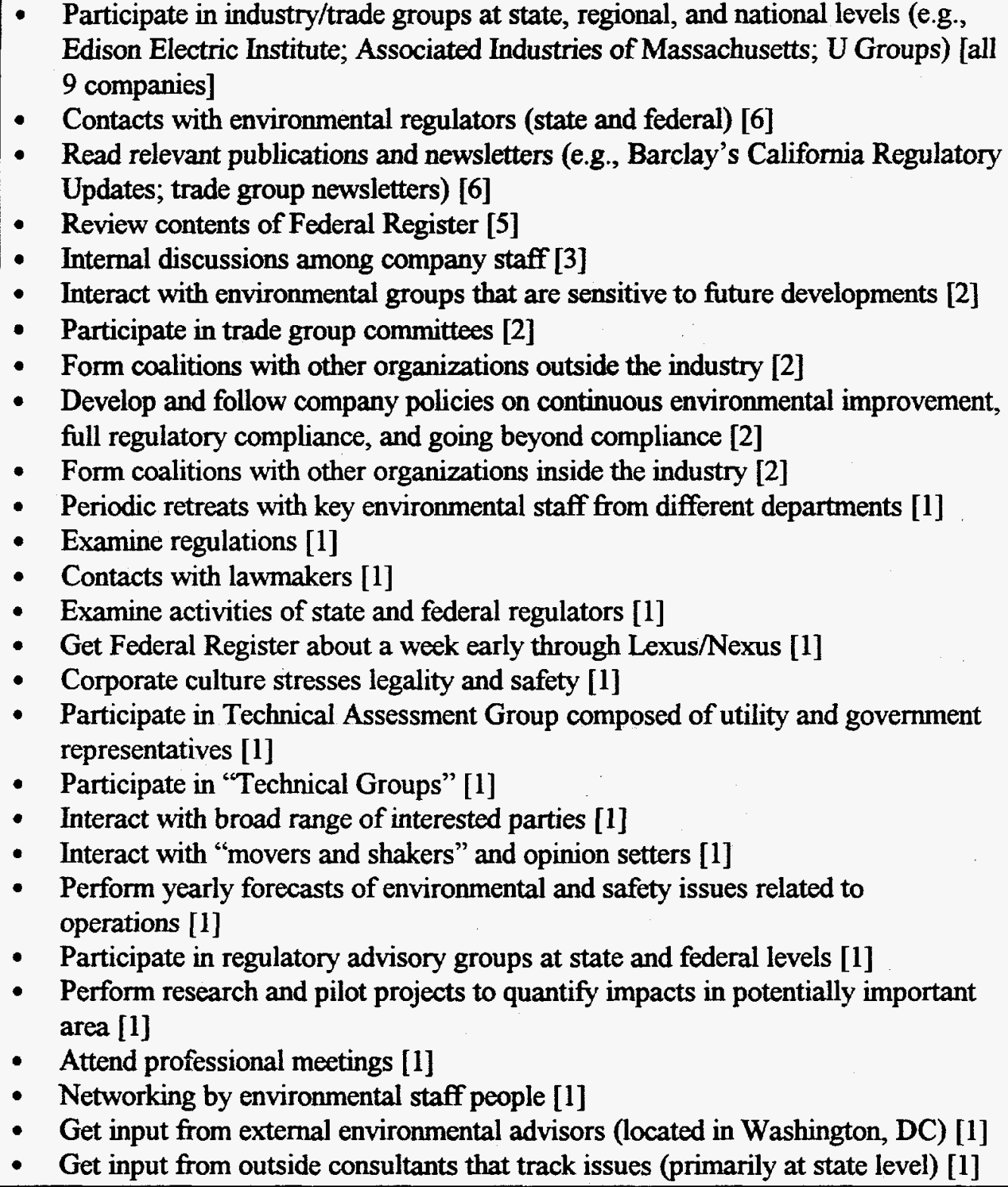 \\
\hline
\end{tabular}

${ }^{1}$ This table includes only those methods/sources volunteered by interviewees in response to an openended question. Accordingly, some companies may engage in various practices in addition to those that they are credited with in this table. 
Table 2: Procedures Used to Track New Environmental Issues and Regulations

\begin{tabular}{|c|c|}
\hline है. & $\begin{array}{l}\text { - Staff within Regulatory Services Group of the Environment, Health, and } \\
\text { Safety Department are assigned to monitor different issues and areas (e.g., } \\
\text { water, air, waste, industrial hygiene, safety). Each distinct issue/area is the } \\
\text { responsibility of a given individual, who tracks an issue from the time it is first } \\
\text { talked about through the time a regulation is proposed and on through passage } \\
\text { of final regulation. } \\
\text { - Outside consultants help track some things, primarily at the state level. } \\
\text { - Activities of Regulatory Services Group are integrated with other departments } \\
\text { (e.g., Environmental Affairs, Law, various product departments). } \\
\text { - Staff of Regulatory Services Group can also be involved in "advocacy" } \\
\text { activities. }\end{array}$ \\
\hline है & $\begin{array}{l}\text { - Company engages in Performance Planning Process at very beginning of every } \\
\text { year, to review previous year's performance and develop plans for coming } \\
\text { year. Process identifies areas of concern (based on company's operations and } \\
\text { emerging issues) to follow in the year ahead. } \\
\text { - Staff in Washington, DC and in seven key operating states are responsible for } \\
\text { tracking issues, under direction of Governmental and Environmental Affairs } \\
\text { Department. Staff consists of engineers and governmental affairs professionals } \\
\text { working together. } \\
\text { - In addition to annual meeting, Governmental and Environmental Affairs } \\
\text { Department conducts monthly program conference calls with all staff as well } \\
\text { as having one-on-one conversations and "small sector" calls. } \\
\text { - Staff are involved at legislative level in Washington, DC and in key states. }\end{array}$ \\
\hline$\stackrel{\#}{\#}$ & $\begin{array}{l}\text { - Advocacy and Awareness group tracks all major issue areas (e.g., air, water, } \\
\text { RCRA). } \\
\text { - Internal "network teams" are established-one team per important issue; } \\
\text { chaired by A\&A group and manned by appropriate staff from all interested } \\
\text { departments. } \\
\text { - Long-term strategies developed by upper level management Steering } \\
\text { Committee. }\end{array}$ \\
\hline 逽 & $\begin{array}{l}\text { - Employ "compliance model" that takes company from issue identification } \\
\text { through regulatory compliance. Director of Regulatory Management and his } \\
\text { staff are responsible for this. } \\
\text { - Restate/revise goals and long-range plan at end of each year. } \\
\text { - Company performs advocacy function, in an effort to influence outcomes. } \\
\text { Washington, DC office does legislative advocacy, while most regulatory } \\
\text { advocacy is performed by home office. }\end{array}$ \\
\hline 를 & $\begin{array}{l}\text { - Employ "lobbyists" in state capitol and Washington, DC. } \\
\text { - Assign staffer in Environmental and Safety Group to keep track of each } \\
\text { potentially-important notice in Federal Register. } \\
\text { - Send word about relevant Federal Register notices to potentially-affected } \\
\text { departments. }\end{array}$ \\
\hline
\end{tabular}




\begin{tabular}{|c|c|}
\hline$\frac{1}{\frac{1}{E}}$ & $\begin{array}{l}\text { - Set up interdisciplinary teams to monitor events and develop strategies in } \\
\text { major regulatory areas (e.g., air and water quality). }\end{array}$ \\
\hline$\frac{\sqrt{3}}{b_{3}}$ & $\begin{array}{l}\text { - Regulatory and Government Affairs Department reviews Federal Register } \\
\text { daily and shares findings with designated representatives from relevant } \\
\text { departments; look at filings from EPA, FDA, OSHA, Department of } \\
\text { Commerce, Department of Justice, and others. } \\
\text { "Issue Management Process" has one individual responsible for each key } \\
\text { issue; this person then shares information with management and other } \\
\text { interested parties. } \\
\text { Each internal department is responsible for environmental quality. }\end{array}$ \\
\hline $\begin{array}{l}\infty \\
\stackrel{\infty}{*} \\
\frac{\pi}{8}\end{array}$ & $\begin{array}{l}\text { The tracking process consists of the following major steps: identify issue; } \\
\text { evaluate issue; assign lead individual; develop team (if necessary); develop } \\
\text { company position; develop action plan; implement action plan; and evaluate } \\
\text { performance. } \\
\text { The above steps are the responsibility of the corporate environmental } \\
\text { department, but input on issues and other assistance, as needed, are sought } \\
\text { from other departments. } \\
\text { - Activities of many federal, state and local agencies are monitored. } \\
\text { - The department works with industry groups on regulatory analysis and action. }\end{array}$ \\
\hline 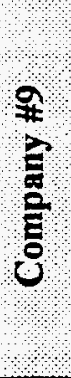 & $\begin{array}{l}\text { - Employ "external advisors" in Washington, DC. } \\
\text { - Staff member in business planning department works on environmental } \\
\text { strategy. } \\
\text { - Staffers from all departments meet regularly to discuss "hot" topics and } \\
\text { strategic issues that might need attention (in monthly "process meetings" and } \\
\text { in retreats held two or three times a year). } \\
\text { - Environmental staffers are integrated throughout the company, in a matrix } \\
\text { arrangement. }\end{array}$ \\
\hline
\end{tabular}

Four companies produces a formal written regulatory outlook on a regular basis. The other five companies do not produce formal regulatory outlooks. Table 3 summarizes major features of the four actual future regulatory outlooks. Of most interest to this project, only one company appears to look several years into the future, the use of probabilities is at best unsophisticated, and there are no indications that any company employs a framework of event tracking categories. The companies themselves reported that their ideal regulatory outlooks would be more farsighted, have a "living document" format, be based on reasonable and 
Table 3. Major Features of Actual "Future Regulatory Outlook"1

\begin{tabular}{|c|c|}
\hline 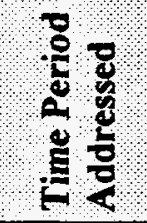 & $\begin{array}{l}\text { - Looks ten years into the future [1] } \\
\text { - Maximum time horizon is two years [1] } \\
\text { - Time frame unspecified [1] }\end{array}$ \\
\hline है. & $\begin{array}{l}\text { - Report [1] } \\
\text { - Notebook of compiled pages on different issues from different sources } \\
\text { within company [2] } \\
\text { - Online data base, called an "Issues Matrix," composed of individual entries } \\
\text { from Regulatory Service staffers assigned to different issues/areas [1] }\end{array}$ \\
\hline 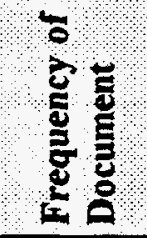 & $\begin{array}{l}\text { - Developed annually [2] } \\
\text { - Developed periodically (not necessarily once a year) [1] } \\
\text { - Updated at least annually, but at different times for different issues [1] }\end{array}$ \\
\hline 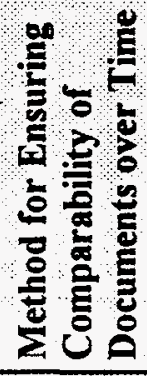 & $\begin{array}{l}\text { - Ensures comparability by having the same individuals do projections year } \\
\text { after year [1] } \\
\text { - Ensures comparability through the use of written instructions [1] } \\
\text { - A single staffer is responsible for tracking the same issue/area over time [1] }\end{array}$ \\
\hline 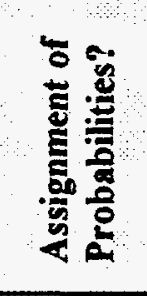 & $\begin{array}{l}\text { - Assigns probabilities to key events } \\
\text { "Low", "Medium", and "High" [2] } \\
\text { - Percentages [1] } \\
\text { - Unspecified format [1] } 10 \text { Scale [1] } \\
\text { - Does not assign probabilities [1] }\end{array}$ \\
\hline 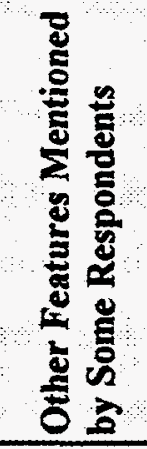 & $\begin{array}{l}\text { - Ranks importance of each issue [1] } \\
\text { - Assigns priorities for addressing each issue [1] } \\
\text { - Identifies implications for company [3] } \\
\text { - Presents strategies/options for dealing with issues/events [2] } \\
\text { - Discusses potential for company to influence outcomes [2] } \\
\text { - Identifies items for which cost and technical data are needed [1] }\end{array}$ \\
\hline
\end{tabular}

${ }^{1}$ This table includes only those features volunteered by interviewees to an open-ended question. Accordingly, some companies' future regulatory outlooks may have features not indicated in this table. 
defensible probabilities (e.g., derived by Delphi techniques), and help companies more explicitly prioritize and decide when to take proactive actions.

The work of people involved in assessing potential future environmental regulatory events is disseminated throughout the companies in various manners. As indicated in Table 4, how information is disseminated depends in part on the degree to which the activity is centralized in the company. For example, in Company \#9, environmental staffers are integrated throughout the company, so that information dissemination can be more informal and done on an as needed basis. At the other extreme, the Governmental and Environmental Affairs Department of Company \#2 conducts seminars and gives presentations to corporate customers on an as needed basis.

\section{Table 4. Ways in Which Information on Future Environmental Issues and Regulations is Disseminated and Used in Decision Making}

\begin{tabular}{|c|c|}
\hline 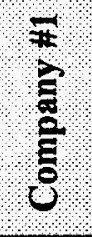 & $\begin{array}{l}\text { - Regulatory Services department uses information in their online data base to } \\
\text { answer questions and prepare customized reports for internal "client" } \\
\text { departments. } \\
\text { - Information provided by Regulatory Services to individual departments is used } \\
\text { in annual budgeting decisions. }\end{array}$ \\
\hline$\frac{\mathbb{A}}{2}$ & $\begin{array}{l}\text { - Governmental and Environmental Affairs Department does seminars and } \\
\text { presentations for operating departments within company (the "customers") on } \\
\text { an "as needed" basis. Explain upcoming regulations and implications for } \\
\text { company operations. }\end{array}$ \\
\hline 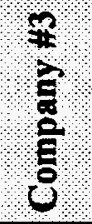 & $\begin{array}{l}\text { - Steering Committee of upper level management receives notebook on emerging } \\
\text { issues and uses this information to develop long-term strategies. }\end{array}$ \\
\hline$\frac{\pi}{8}$ & $\begin{array}{l}\text { Director of Regulatory Management meets monthly with representatives from } \\
\text { business units and manufacturing organizations to present information on } \\
\text { potential new regulations and to make assignments for advocacy work. } \\
\text { Compliance and Support staff come back to Regulatory Management } \\
\text { Department with implications of rules to help in advocacy efforts. }\end{array}$ \\
\hline
\end{tabular}




\begin{tabular}{|c|c|}
\hline 施 & $\begin{array}{l}\text { - Yearly written forecast goes to upper management and all functional directors, } \\
\text { managers of power plants, and environmental engineers. } \\
\text { - Yearly written forecast is used in developing business plans and goals for the } \\
\text { coming year. }\end{array}$ \\
\hline & $\begin{array}{l}\text { Environmental regulatory teams within each separate business unit feed } \\
\text { information into business plans (a decentralized process). } \\
\text { Project manager and lead officer present recommendations to upper } \\
\text { management. }\end{array}$ \\
\hline \#. & $\begin{array}{l}\text { - Staffers and managers learn the importance of environmental issues through } \\
\text { interacting with each other concerning those issues-the process is important. }\end{array}$ \\
\hline$\stackrel{\infty}{*}$ & $\begin{array}{l}\text { - "Future Regulatory Outlook" would be used to identify areas for environmental } \\
\text { R\&D. } \\
\text { - "Future Regulatory Outlook" would be used to guide procurement of pollution } \\
\text { control equipment. } \\
\text { - "Future Regulatory Outlook" would be used for strategic planning. } \\
\text { - "Future Regulatory Outlook" would be used for allocating resources. }\end{array}$ \\
\hline है: & $\begin{array}{l}\text { - Environmental staffers are integrated throughout the company. } \\
\text { - Information on issues is presented to CEO to keep him informed. }\end{array}$ \\
\hline
\end{tabular}

Most of the companies reported that their methods work well. Most companies report that nothing or only minor items fall "through the cracks." In one case, a new U.S. Department of Transportation (DOT) regulation related to hazardous wastes was missed because that agency was not routinely monitored. This situation indicates that this company is also not anticipating future environmental regulations that could emanate from DOT. Another company reported that sometimes it has been difficult to anticipate the severity or inflexibility of a new regulation. A third company noted that the methods work fine but that it faces cultural problems in getting facilities managers to take advice from the centralized corporate office. Two companies that are also satisfied with the methods find that the results are only marginally effective in influencing outcomes and company policy. 


\subsection{OBSERVATIONS}

From a methodological viewpoint, the procedures employed by these companies can be improved. As noted above, the use of probabilities is not widespread and are based on simple approaches when undertaken. No company interviewed uses formally assessed subjective probabilities and it does not appear that the probabilistic information that is collected is used in any further calculations. In only one case is the time frame of the assessment process greater than two years. Two years is generally not enough of a lead time for companies to undertake strategic actions related to preparing for or influencing events (e.g., identifying, collecting, or analyzing data; developing response strategies; getting involved in policy making; planning major capital investments to implementing extensive research and development projects). Undertaking tracking and assessment of events over a longer time frame can be facilitated by a conceptual framework that describes how events move from possibility to probability to actual occurrence, as is presented in the next section.

Sources of assessment information are generally well known for events likely to happen in the near-term. It does not appear that unconventional sources for ideas for over the horizon types of events are frequently tapped. Dissemination of information throughout the companies appears well in-hand. However, how the information is processed to facilitate anticipatory actions by the various corporate customers can be improved. The key to this improvement is to explicitly represent how urgent is it for the various parts of the organization to engage proactive behaviors today in response to the information at hand. The methodology presented below addresses this challenge.

As a final comment, one can argue that more and more companies will begin to engage in assessment activities and that the methods employed will become more sophisticated over time. Those companies adopting the most effective assessment techniques will have a competitive advantage. 


\section{ASSESSMENT APPROACH}

This section presents a methodical, repeatable approach to assessing potential future environmental regulatory events that addresses many of the opportunities for improvement identified in the previous section. The approach explicitly tackles five difficult issues:

- semantics;

- tracking;

- uncertainty representation;

- prioritization; and

- process.

Semantics is a foundational issue. In everyday, informal conversation communication is often inexact. People will often use the same words to mean different things and use different words to mean the same thing. In an informal setting, a certain degree of mis-communication can be tolerated. In an assessment and tracking setting, such informality can lead to major misunderstandings, confusion, and inefficiencies. For example, use of words such as issue and scenario can often be confusing and frustrating if all discussants have not agreed to their definition. Thus, the first challenge is to set out a rigorous semantics, an associated framework, of key concepts in the assessment and tracking scheme (Section 3.1).

An ideal assessment system would track potential future environmental regulatory events from their first glimmer of possibility to the very minute the events come into being. The approach, therefore, needs a framework for people to understand where in the process of moving from glimmer to being an event resides. Such a framework is presented in Section 3.2.

Uncertainty is an inescapable element in assessing potential future environmental regulatory events. Decision makers desire to know exactly when in the future events will occur and 
exactly what form the events will have (e.g., what exactly the emission standards will be). The best one can do is to place probabilities on when events may occur and over the various incarnations of the event. This approach makes innovative use of lower and upper probabilities to represent uncertainties about events and their incarnations (Section 3.3).

The next challenge is the assessment bottom-line: prioritization. In a perfect world, organizations will act proactively to avoid unnecessary consequences of new environmental laws and regulations. It is in an organization's best interests not to wait until it is too late and thereby lose opportunities for cost savings and competitive advantages. Nor do organizations want to make decisions prematurely, which might result in wasted investments and inefficient allocation of resources. In addition, top-level decision makers do not want to spend their time on minor issues. All of these points indicate that the assessment approach needs a prioritization component to indicate to decision makers which potential future environmental regulatory events require their utmost attention. The action prioritization scheme presented in Section 3.4 builds on the first three elements of the overall approach.

The final two parts of this section address implementation issues. Section 3.5 tackles the problem of communicating complex tracking and uncertainty information to busy people using visualization techniques. Section 3.6 details the step-by-step process needed to use the assessment methodology presented in the previous sections.

\subsection{ISSUES, EVENTS AND SCENARIOS: KEY ASSESSMENT CONCEPTS}

The semantics underlying this assessment approach has four central concepts: issues; events; scenarios; and drivers. Their relationships are shown in Figures 1 and 2. Their definitions follow: 


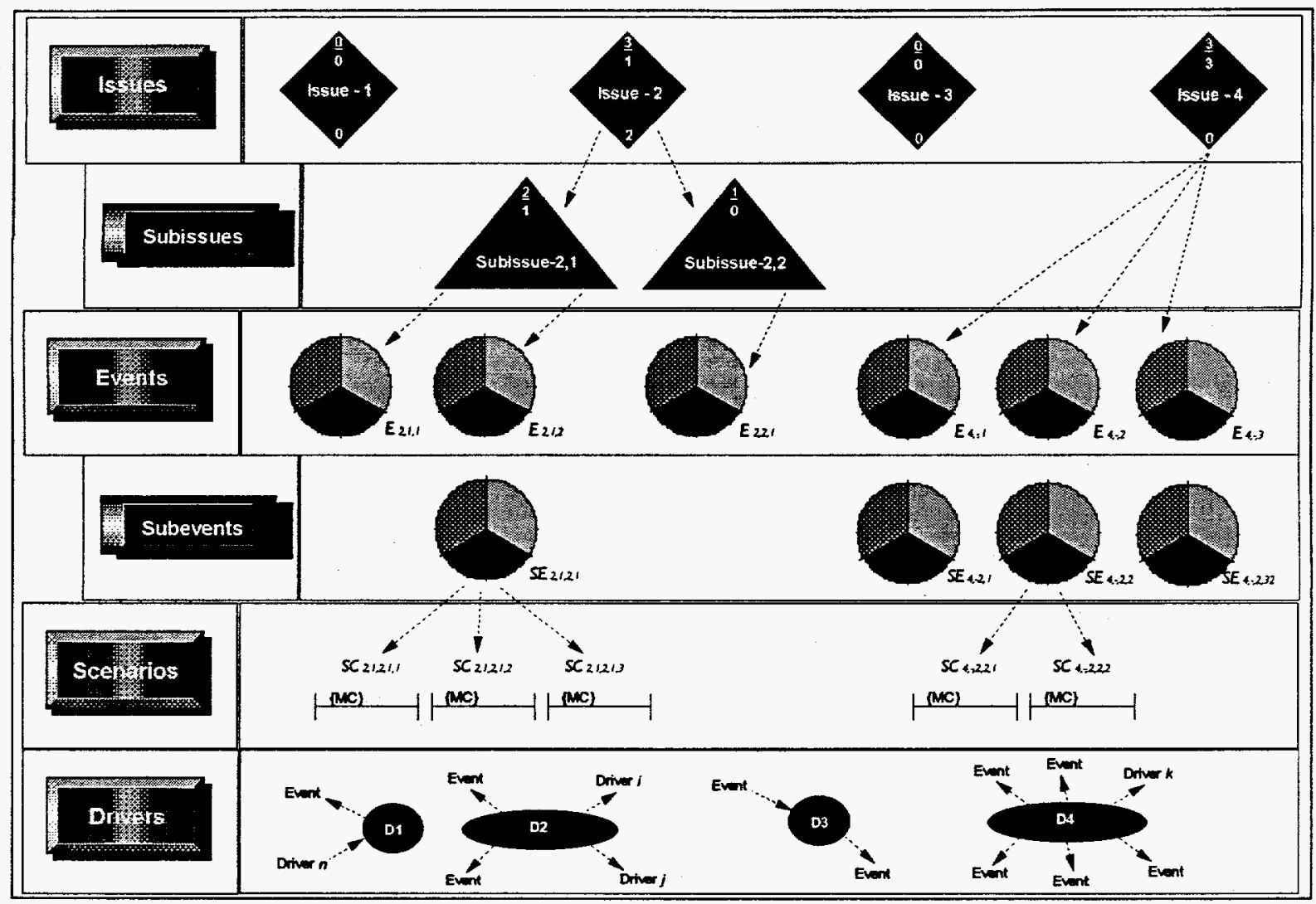

Fig. 1. Schematic representation of major assessment methodology concepts.

ISSUES: These are matters of importance to the organization. In today's environmental frame, issues of importance include, but are not limited to: tropospheric ozone, global climate change, fine particle pollution, wastewater discharge, operation of ash ponds, operation of cooling water intakes, regulation of dams, and human respiratory health. An example of an emerging issue is endocrine disrupters. How important an issue is to an organization can be discussed and disputed. Papers can be written on issues. What one cannot do with issues is to place probabilities on them, because they are not events or scenarios, which are discussed next.

EVENTS: An event is something which occurs and comes into being. Generic types of environmental regulatory events are laws, regulations, regulatory policies or guidance, and judicial opinions. The occurrence or non-occurrence of an event can be predicted. 


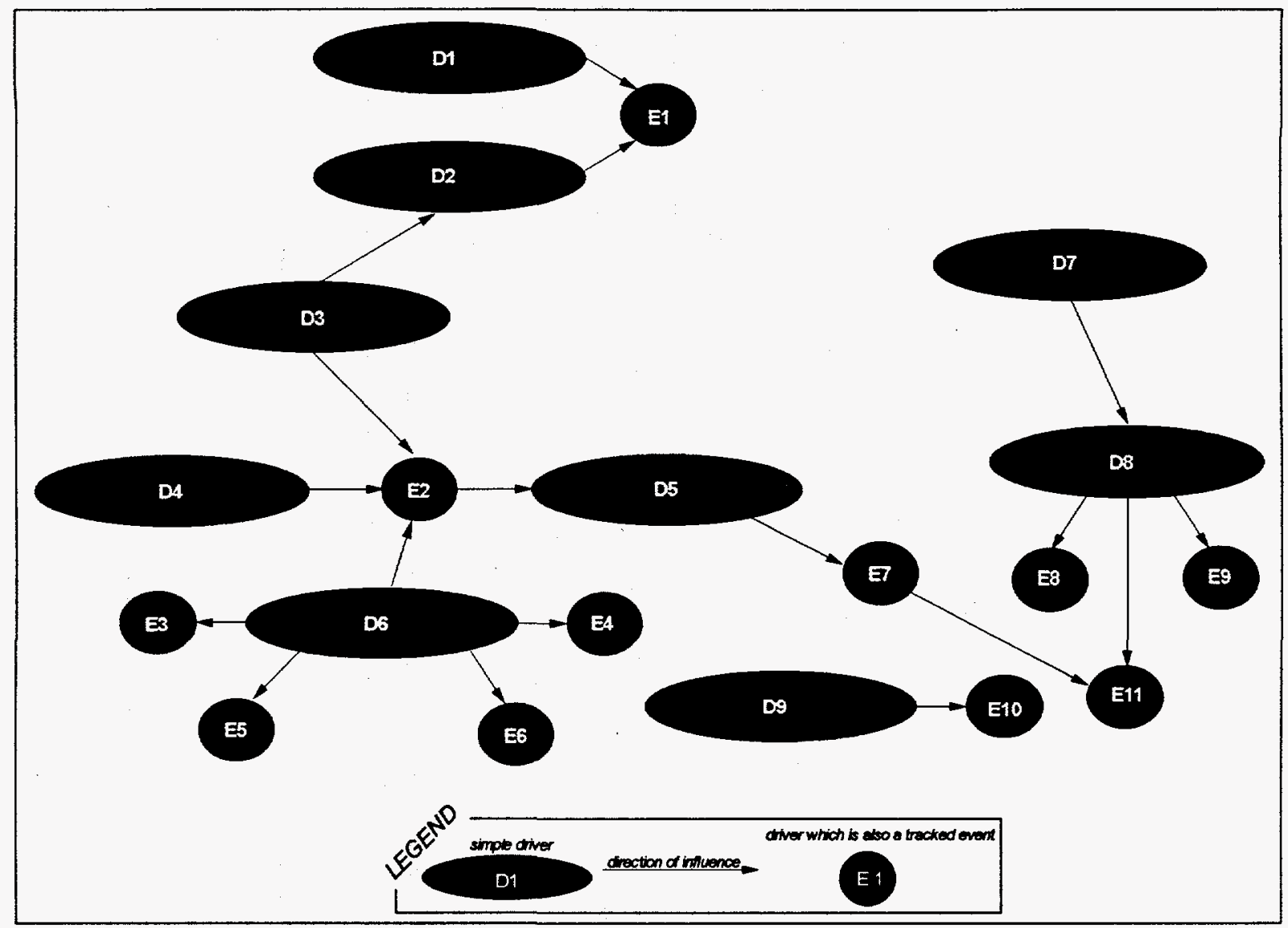

Fig. 2. Example relationships between drivers and events.

Probabilities can be associated with the occurrence or non-occurrence of an event. Thus, probabilities can be assessed for the occurrence or non-occurrence of specific environmental regulatory events such as the, reauthorization of the Clean Water Act, the reauthorization of Superfund, and EPA issuing new power plant intake standards. Events are associated with issues.

SUB-EVENTS: Often regulatory events of importance to an organization are quite complex. For example, new environmental legislation or regulation may have numerous sections and sub-sections, with only a subset being of importance to the organization. The organization may only wish to track a component of an event, which is referred to here as a subevent. A subevent can only occur if the entire event occurs. 
SCENARIOS: These are explicit descriptions of the possible outcomes of potential events (or subevents). Only one description of a possible outcome of an event can become true. Thus, only one scenario associated with an event can become true. The richer the descriptions associated with an event or subevent, which are defined here as scenario elements, the greater the number of possible scenarios there will be. For example, in fashioning a regulation, which is defined as an event within this semantic, EPA may have many elements to consider. Should the regulation be applied industry-wide or site by site? What should the level of emissions reductions be, $25 \%, 50 \%, 75 \%$ ? Should a market mechanism be applied? If so, should trading be allowed within a sector, within all sectors within a state, among all sectors within a region? One scenario for this hypothetical regulatory event would posit an answer to each of these element questions (e.g., site by site, 50\%, no trading). Probabilities can be assessed over scenarios, given that the event becomes true.

As shown in Figure 1, issues, events, and scenarios have specific relationships to each other. Any number of issues can be identified. Each issue may have any number of events that need to be tracked. Each event needs to have at least two scenarios. A complete scenario specification would result in a combinatorial number of scenarios, calculated from the number of elements and the number of values each scenario element could take.

DRIVERS: These are causes for events to occur or not to occur. For example, severe weather events have a way of 'causing' regulatory events to occur, as do stories in the media, results of an important study of the effects of a chemical on human health, and the change in political parties holding majorities in legislatures. Drivers act to increase or decrease the probability of an event occurring, and the probability of which scenario will come true if the event becomes true. As indicated in Figure 2, drivers can have very complex relationships with events and each other. Sometimes one driver influences another driver (e.g., D3 on D2), which in turn influences an event of importance to the organization (e.g., D3 on E2). Some drivers are particularly important because they 
influence several events (e.g., D6 on E2, E3, E4, E5, and E6). Lastly, events can act as

drivers for other events (e.g., E7 on E11). It behooves an organization to track important drivers and their relationships.

\subsection{TRACKING EVENTS OVER TIME: DATABASE ELEMENTS}

There is a discernable process that describes how potential environmental regulatory events metamorphose over time from glimmers of possibilities to coming into being. Understanding this process can help to organize the tracking of potential events over time, to forecast when regulatory events may eventually occur, and to help guide what information or intelligence needs to be gathered to indicate where in the process a regulatory event sits. A suggested tracking framework has the following four categories of events:

1. Over the Horizon:. Potential regulatory events that have a glimmer of possibility, even if only in the imagination of one who has responsibility for tracking potential future environmental regulatory events, are placed in this tracking category. One can scan for over the horizon events in the scientific research literature, in the futures literature, in speculative Internet user groups, and in the general science fiction and other literatures. One can brainstorm potential regulatory events that could emanate from items of potential importance to the organization and place these events in this category. Over the horizon events are usually discussed in only simple and general terms. A few researchers may be worrying about the issues associated with these potential events from a theoretical perspective and possibly conducting limited experimental studies. It may be difficult to define scenario elements for events in this category, so only general notions of the outlines of the events and the consequences to the organization of the events may be specifiable. Since over the horizon events are so speculative, it is recommended that probabilities not be assessed over their occurrence. 
2. On the Horizon: Potential environmental regulatory events placed in this category have a definite chance of coming into being. This is because a scanning of appropriate information sources indicates that issues associated with the events are receiving more attention from scientists and others. For example, many more scientific studies may have been initiated. Advisory and/or task groups may have been formed. The issues may have been discussed more frequently at conferences and raised in science and practitioner literature. The events being tracked by the organization may actually have been specifically mentioned within the policy community and gelled into specific proposals for legislation and/or regulations. However, with respect to on the horizon events, there is no clear consensus that anything needs to be done. By and large, politicians have not begun to push the event and/or regulatory agencies have not begun to actively consider new regulations.

3. On the Screen: These events have gained the attention of decision makers, be they legislators or regulators. This is because important drivers of the event have begun to have their influence. For example, several important scientific studies may have been completed or a public health scare may have occurred or an adverse environmental event may have galvanized public attention. This is a period of contemplation and posturing for the decision makers. Is it worth their while to expend political capital and/or staff resources to make these events happen? This is a period when the decision makers are openly discussing the issues surrounding on the screen events and the possibility of the regulatory event itself. They are beginning to articulate their preferred scenarios for the events, to ascertain levels of political support and/or technical feasibility. Other indications that events are on the screen can be drawn from a scanning of editorials, and statements of priorities by non-governmental organizations.

4. On the Agenda: Decisions regarding events in this category are being actively pursued by legislative, regulatory bodies, environmental interest groups, and/or the courts. 
Dates by which decision(s) must be made or are expected to be made are known. The regulatory agency is in the advanced process of formulating or evaluating scenarios related to the regulatory event or sub-event. Legislation has been introduced fleshing out one or more scenarios of a legislative event or sub-event. Supreme Court selects case for review or grants motion to review case or Federal or State Appellate Court has scheduled to hear case. For on the agenda events, one has a palable sense of when the fate of the event will be determined.

An important task of this assessment approach is to classify events into one of the four categories: over the horizon, on the horizon, on the screen, and on the agenda. Over time, the organization needs to track the events as they move from one category to the next, and maybe back again. The organization needs to continually assess the validity of the scenario elements because over time the set of elements could change and values for the elements could change. The organization also needs to keep track of several other aspects of the events.

For completeness, it is recommended that the following be tracked for each event (definitions for these database elements can be found in Appendix A):

- event name;

- associated issue (e.g., tropospheric ozone);

- category (e.g., on the screen);

- when to reassess the status of this event;

- sources of intelligence about the event (e.g., publications);

- drivers (e.g., scientific studies);

- volatility of drivers (e.g., high associated with media drivers);

- influence of the drivers on the event (e.g., high);

- probabilities of occurrence over time (see Section 3.3);

- scenario elements;

- constructed scenarios; 
- probabilities of scenarios;

- consequences to the organization of scenarios;

- urgency of the event to the organization's decision makers (see Section 3.4);

- degree of organization's ability to influence the event; and

- action priority (see Section 3.4).

\subsection{UNCERTAINTY REPRESENTATION METHODS}

The approach used to capture uncertainty associated with events is illustrated in Figure 3. This figure depicts six example stories to describe circumstances surrounding an event over time. The $y$-axis of each graph represents probability, which ranges from 0.0 to 1.0. The $x$-axis represents time, from now to some point in the future. The units of time can be years or whatever seems most appropriate for the tracking framework. The figures represent lower and upper conditional probabilities over time and are interpreted as such: the lower and upper probabilities of $E_{i}$ occurring in the next time period, $t_{i+1}$, given that event $E_{i}$ has not yet occurred by time $t_{i}$.

The major assumption is that when an analyst is asked about the uncertainty associated with an event, the analyst will first imagine a story about how the event could occur over time. Such a cognitive exercise is common and effective and has been a topic of past research by cognitive psychologists. The features or circumstances about the story will, then, inform the analyst about uncertainties about the occurrence of the event. (Exhibit 1 provides a brief explanation of lower and upper probabilities.) 
Let us examine the first story. This story associated with the event is labeled "Inevitable." It is interpreted as follows: in the near term, the likelihood of the event occurring is very low; as time progresses there is much uncertainty about whether the event could happen, possibly due to unpredictable drivers; and finally, in the longer-term, the occurrence of the event is seen as greatly increasing. The tails of the curves indicate that if the event has not occurred by some time $t_{i}$, then with much certainty the event will occur in the next time period.

The next story, labeled

"Speculative," depicts a story where far into the future, the event has a low likelihood of occurrence. The tail end of these figures indicate that if the event has not occurred by some time $t_{i}$, it is also not likely to occur in the next time period. The third story, labeled "Count on it," is just the
The approach adopted herein focuses on representing uncertainties associated with events and scenarios. There are numerous methods available with which to represent uncertainty, including classical probability, fuzzy sets, and certainty factors. We have chosen methods that fall within the field of imprecise probability. Imprecise probability is a generalization of classical, or using our terminology, precise probability. Imprecise probability offers users more flexibility in representing large degrees of uncertainty through the mechanism of lower and upper probabilities.

For purposes of illustration, let us assume one has an urn with 100 balls inside, which come in two colors, blue and red. The question is what is the probability of drawing out a red ball. When one has a great deal of information, for example knowing that 50 balls are red and 50 balls are blue, then one can assign a single probability to the event of drawing a red ball, in this case a single probability of 5 . However, let us assume that the number of balls of each color is unknown or only known partially. In these instances, using lower and upper probabilities is a more effective way of expressing one's knowledge For example, if one knows that 20 balls are red and 20 balls are blue, then one can assign a lower probability of 2 to drawing a red ball and an upper probability of 8 . If one has no knowledge other than that there are 100 balls and they could be all red or all blue or any combination in between, then one can assign a lower probability of 0 and an upper probability of 1.0. As one's knowledge increases over time, then the range between the lower and upper probability closes until the two are equal, as they would be in the very first case outlined above.

Lower and upper probabilities are an excellent method for representing uncertainty about future regulatory events because in the out years there is much uncertainty, and over time in many cases the uncertainty will be reduced. Thus, one can envision for some very uncertain events situations where lower and upper probabilities are wide apart and for some almost certain events, lower and upper probabilities are both close to 1.0 .

Exhibit 1. A Brief Explanation of Lower and Upper Probabilities.

opposite. Although the event is unlikely to occur in the very near term, the story indicates that the likelihood increases dramatically after that. The "Anything goes" story depicts great uncertainty after the very near term. Maybe this event is driven wholly by fickle public 

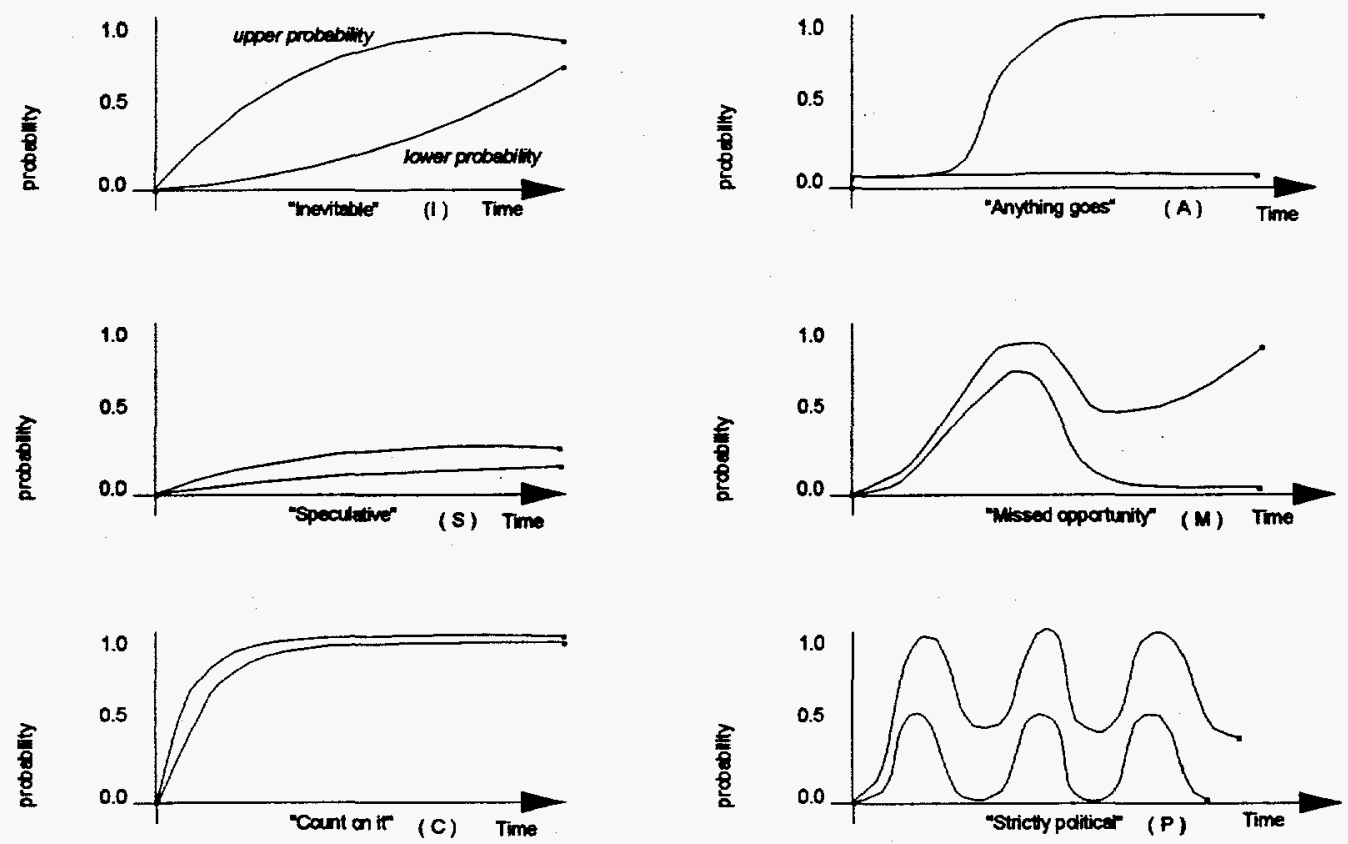

Fig.3. Example probability of event occurring stories.

opinion. The fifth story, "Missed opportunity," depicts a story common to the legislative arena. In this case, momentum is building up to the passage of a law. There is a good chance it will pass at the end of the session, but there are many compromises to be made and many commitments are shaky or unknown. If the law does not pass, then an opportunity is missed and there is great uncertainty in the longer-term about the law's fate. In the "Strictly political" case, this process is replicated every two or so years.

Prior to the process to assess the lower and upper conditional probabilities, a guiding story needs to be chosen and revised, as appropriate, and then the probabilities need to be specified. A regulatory analyst can do this alone or with colleagues. Also, a facilitator can be arranged to lead one or more analysts through the process. This choice is discussed more in Section 5 of this report. The probabilities can be assessed either in a tabular form, as shown in the examples in Section 4, or graphically. In the latter case, figures such as those shown in Figure 
3 are sketched out for the event in question. It is recommended that before the conditional probabilities are elicited that a thorough analysis of the event's drivers be conducted (also see the examples in Section 4) and that the event be categorized as discussed in Section 3.2. These exercises will bring to light all important factors needed to assess the probabilities.

Lower and upper probabilities can also be assessed over the set of scenarios associated with each event. Although these probabilities are not used in subsequent calculations (which are discussed in Section 3.4), the probabilities can be valuable in helping the organization better understand the likely outcomes (and potential consequences) of probable regulatory events. In this case, the question is: given that event $\mathrm{E}_{\mathrm{i}}$ will occur, what are the lower and upper probabilities associated with each scenario becoming true. As noted in Section 3.1, scenarios are built from scenario elements. Each scenario has a unique combination of values for the scenario elements. To be exhaustive and complete, lower and upper probabilities would need to be assessed for each of a potentially very large number of scenarios. To simplify this exercise, one can construct a much smaller set of scenarios, maybe between five to ten. As illustrated in the examples in Section 4, one might construct best and worst case scenarios (which might be unlikely but are useful in bounding potential consequences for the organization) and several likely scenarios.

When using lower and upper probabilities, there are three conditions that need to be met. First, the sum of the lower probabilities assessed over all potential scenarios needs to sum to less than or equal to one. Second, the sum of the upper probabilities assessed over all potential scenarios needs to sum to greater than or equal to one. Lastly, for each scenario, the lower probability needs to be less than or equal to the upper probability. (See B. Tonn and C. Wagner 1995. "Handling Uncertainty in Quantitative Estimates in Integrated Resource Planning," ORNL/CON-388, Oak Ridge National Laboratory, Oak Ridge, TN, January.) 


\subsection{ASSESSING ACTION PRIORITIES}

This task is much more challenging than one might think. As mentioned in the introduction of this section, decision makers in the organization do not want to make premature decisions nor wait too long to take action. They do not want to waste time on inconsequential decisions. Uncertainty about when regulatory events will occur greatly complicates this already complex problem. It is the responsibility of those assessing future potential environmental regulatory events to inform decision makers and gain their attention given these guidelines.

To capture this challenge, the recommended approach is to associate a measure of action urgency with each potential future environmental regulatory event. Action urgency is defined as the importance to the organization of taking action of some sort in reference to a potential regulatory event at different periods of time before the event occurs. For descriptive purposes, let us assume that for an event that will occur far into the future, there may be little or no urgency to act now with regard to the potential event. On the other hand, if it appears that the same event could occur in the next two or three years and there are proactive actions that the organization could be taking now, then the level of action urgency of the event would be high.

It is important to note that complex organizations undertake a plethora of different actions and that any number of different proactive actions may be taken in response to a potential future environmental regulatory event. One normally thinks of investments in capital equipment or divestments of assets as the quintessential proactive action with respect to environmental regulatory events. Other potential actions include: implementing a research project or program; changing operations; and employing means to influence the outcome of

the event. Regulatory analysts also need to consider actions related to informing top-level decision makers and even to decide when to begin to analyze a potential regulatory event. It is possible, then, for one potential regulatory event to be associated with multiple measures of action urgency. 


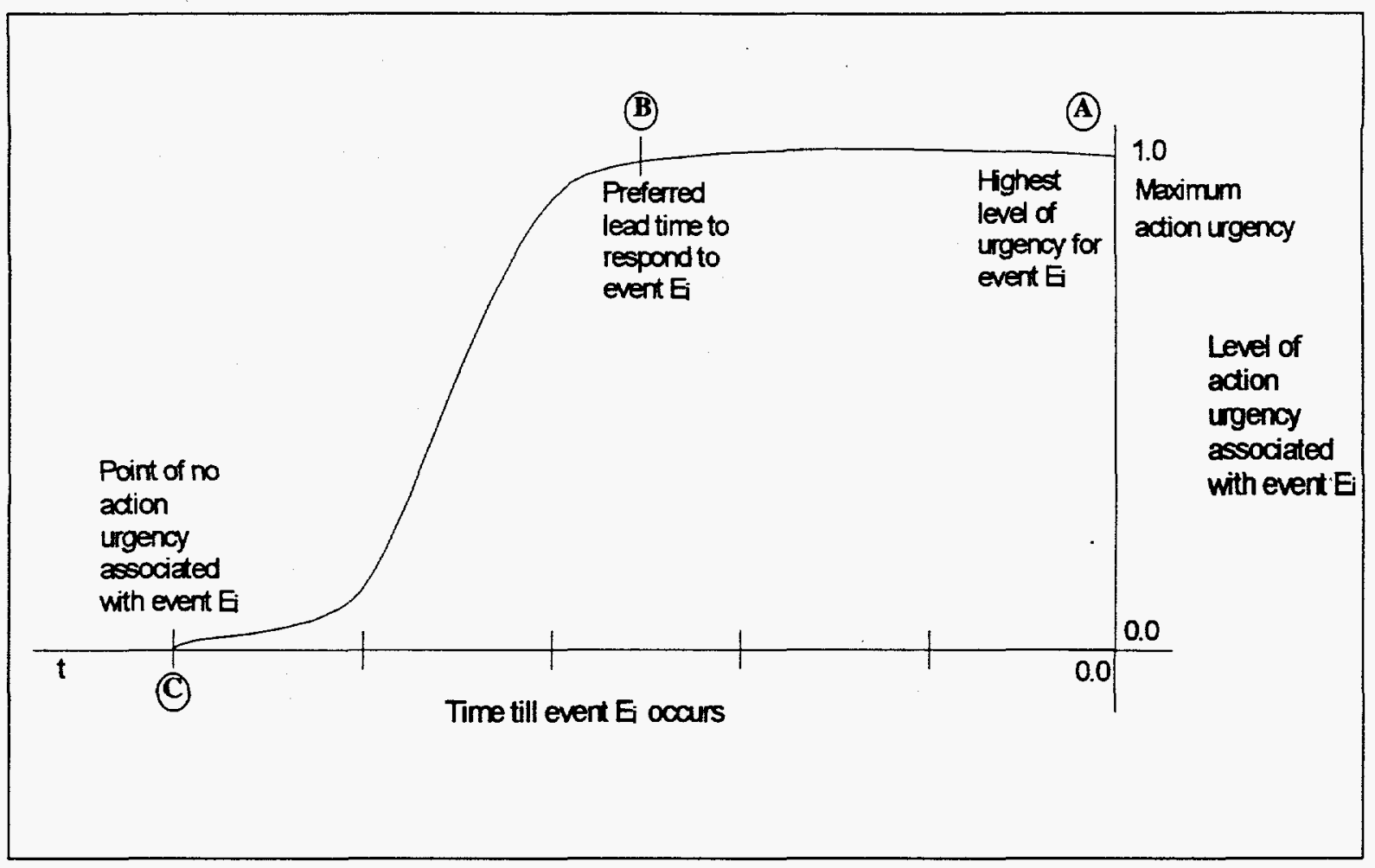

Fig. 4. Generic measures of action urgency.

Figure 4 illustrates a generic curve for representing the action urgency of a potential regulatory event to some part of the organization. The $y$-axis is the level of action urgency, defined to range between 0.0 and 1.0 , with the former representing no action urgency and the latter representing maximum action urgency. The $x$-axis is the time till the event occurs, assuming no uncertainty about when the event will occur. Uncertainty about this is dealt with below. Point $A$ on the figure indicates the highest level of action urgency this potential event can have with respect to a certain decision context for some part of the organization. After Point $B$, the action urgency curve begins to decrease, to where it reaches zero at Point $C$. Point $B$ can be understood as the minimum preferred lead time before the event will happen that proactive action should be taken. At a time before Point $\mathrm{C}$, there is no need to act. The period between Points B and C allow for some discretion in whether to act. One would expect more discretion built into events that have more action urgency and longer lead times than for events with less action urgency and smaller lead times. 

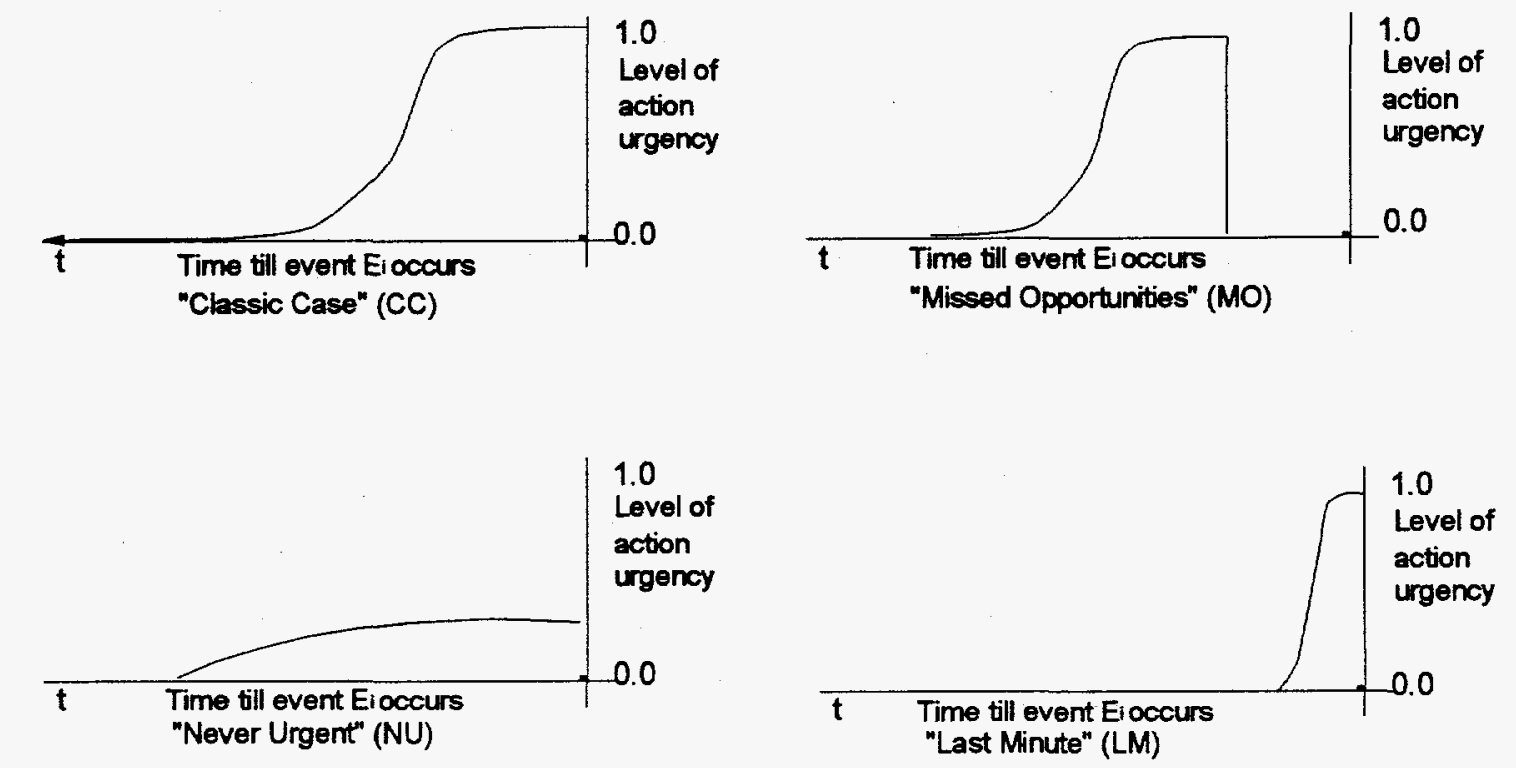

Fig. 5. Action urgency stories.

Similar to the "stories" used to assess the probabilities of the events occurring, one can develop a set of stories for analysts to use to guide their assessments of action urgency for events. A set of action urgency stories is shown in Figure 5. The small figure in the upper left replicates Figure 4. It is labeled "Classic Case" because it is assumed that measures of action urgency for most events will take this shape. The small figure in the upper right indicates that at some point in time, there is a "Missed Opportunity" for proactive action, resulting in a level of zero action urgency for some period of time right before the event will occur. The small figure in the lower left indicates that for some events proactive action is "Never Urgent." Lastly, the small figure in the lower right illustrates an event for which only "Last Minute" actions are appropriate. For illustrative purposes, the examples in Section 4 contain estimates of action urgency.

The Action Priority $\left(A^{*}\right)$ of an event to the organization is a function of the measure of action urgency and the probability of the event occurring over time. Thus, an algorithm is needed to 
combine these two elements to produce a measure of action priority. The algorithm has three components:

- one which converts the conditional lower and upper probabilities for an event occurring at some point in time to lower and upper cumulative distribution functions;

- a second which calculates lower and upper expected action urgencies for an event; and

- a third which calculates an event's action priority.

\section{Convert Conditional Probabilities to Cumulative Distribution Functions}

As explained in Section 3.3, the regulatory analysts assess lower and upper conditional probabilities concerning when in time an event may occur. Let $G$ and $\bar{G}$ represent the lower and upper conditional probability functions, respectively, specified over a time period of $n$ years. Let $Y$ represent the random variable recording the year in which the event of interest occurs and let $Y$ take the possible values $1,2,3, \ldots . n$. Then the following formulas define the two conditional probability functions:

$$
\begin{aligned}
& G(j)=P(Y \leq j \mid Y>j-1) \\
& \bar{G}(j)=\bar{P}(Y \leq j \mid Y>j-1)
\end{aligned}
$$

(See Appendix B for further discussion.)

To calculate expected values for random variables, cumulative distribution functions ( $c d f$ ) are required. Let $E$ and $\bar{F}$ represent lower and upper cumulative distribution functions. In this case, lower and upper $c d f$ s are needed over the random variable $Y$. As explained in Appendix $\mathrm{B}, \underline{G}$ and $\bar{G}$ do not uniquely determine $E$ and $\bar{F}$. Thus we take the following "rough" approach. The following formulas define lower and upper cumulative distributions function: 
(3)

$$
\underline{E}(j)=\underline{P}(Y \leq j)
$$

(4)

$$
\bar{F}(j)=\bar{P}(Y \leq j)
$$

Define "rough" lower and upper $c d f s F^{*}$ and $\overline{F^{*}}$ by the following recursive formulas:

(i) $\underline{F}^{*}(1)=\underline{G}(1)$, and

(ii) $\underline{F^{*}}(j)=E^{*}(j-1)+\underline{G}(j)\left[1-E^{*}(j-1)\right]$ for $j \geq 2$; and

(i) $\overline{F^{*}}(1)=\bar{G}(1)$, and

(5)

(ii) $\overline{F^{*}}(j)=\overline{F^{*}}(j-1)+\bar{G}(j)\left[1-\overline{F^{*}}(j-1)\right]$ for $j \geq 2$; and

\section{Calculate Rough Lower and Upper Expected Action Urgencies}

Let $u(j)$ denote an appropriate measure of the urgency of acting now (i.e., at the beginning of year 1 ) were the event of interest to materialize sometime during year $j$. One then calculates the "rough lower expected action urgency" $E^{*}(U)$ and the "rough upper expected action urgency" $\overline{E^{*}}(U)$ by the formulas:

$$
E^{*}(U)=u(1) \underline{E^{*}}(1)+\sum_{j=2}^{n} u(j)\left[\underline{F^{*}}(j)-\underline{F^{*}}(j-1)\right] \text {, and }
$$

$$
\overline{E^{*}}(U)=u(1) \overline{F^{*}}(1)+\sum_{j=2}^{n} u(j)\left[\overline{F^{*}}(j)-\overline{F^{*}}(j-1)\right]
$$

\section{Calculate Action Priorities}


How an organization uses lower and upper expected values of action urgency over potential future environmental regulatory events depends, in part, on the organization's attitudes towards risk and uncertainty. A maximally risk averse organization may only use the upper expected values of action urgency. This means that the organization would make decisions based on worse case outcomes that events will occur at the upper bounds of their probabilities. Such a strategy, however, may prove inefficient in the long run, as always preparing for worst cases, especially in a very uncertain environment (i.e., where there are large ranges between the lower and upper conditional probabilities), may be quite costly. On the other hand, making decisions based solely on the lower expected values of action urgency may prove too risky for the organization. Thus, a way of balancing lower and upper expected values of action urgency may be required.

This problem can be handled by choosing a number $\alpha$, with $0 \leq \alpha \leq 1$ and constructing from $\underline{E^{*}}(U)$ and $\overline{E^{*}}(U)$ the "rough action priority" $A^{*}$ associated with the event in question, defined by the weighted average

$$
A^{*}=\alpha E^{*}(U)+(1-\alpha) \overline{E^{*}}(U)
$$

The number $\alpha$ is an index of risk adversity. The larger $\alpha$ is the more credence analysts give to the lower probabilities that describe when the event could occur. The lower $\alpha$ is the more weight is given to making decisions that are based on the assumption that the event will occur.

This equation indicates that the action priority for an event ranges from 0.0 to 1.0. Experience is needed to observe how events will be distributed within this range. Part of this answer will come from the relative proportion of on the horizon versus on the agenda events that an organization is tracking.

A more complete discussion of the equations and their derivation is found in Appendix B. 


\subsection{REPORTING ASSESSMENT RESULTS}

It is vitally important to find innovative and effective ways of presenting information to an organization's decision makers concerning future potential environmental regulatory events. The information needs to be concise, visual, and maximally informative. Summary displays with the ability to delve into more detail as requested are particulary effective. Figure 6 presents one suggestion for a summary display for top-level decision makers.

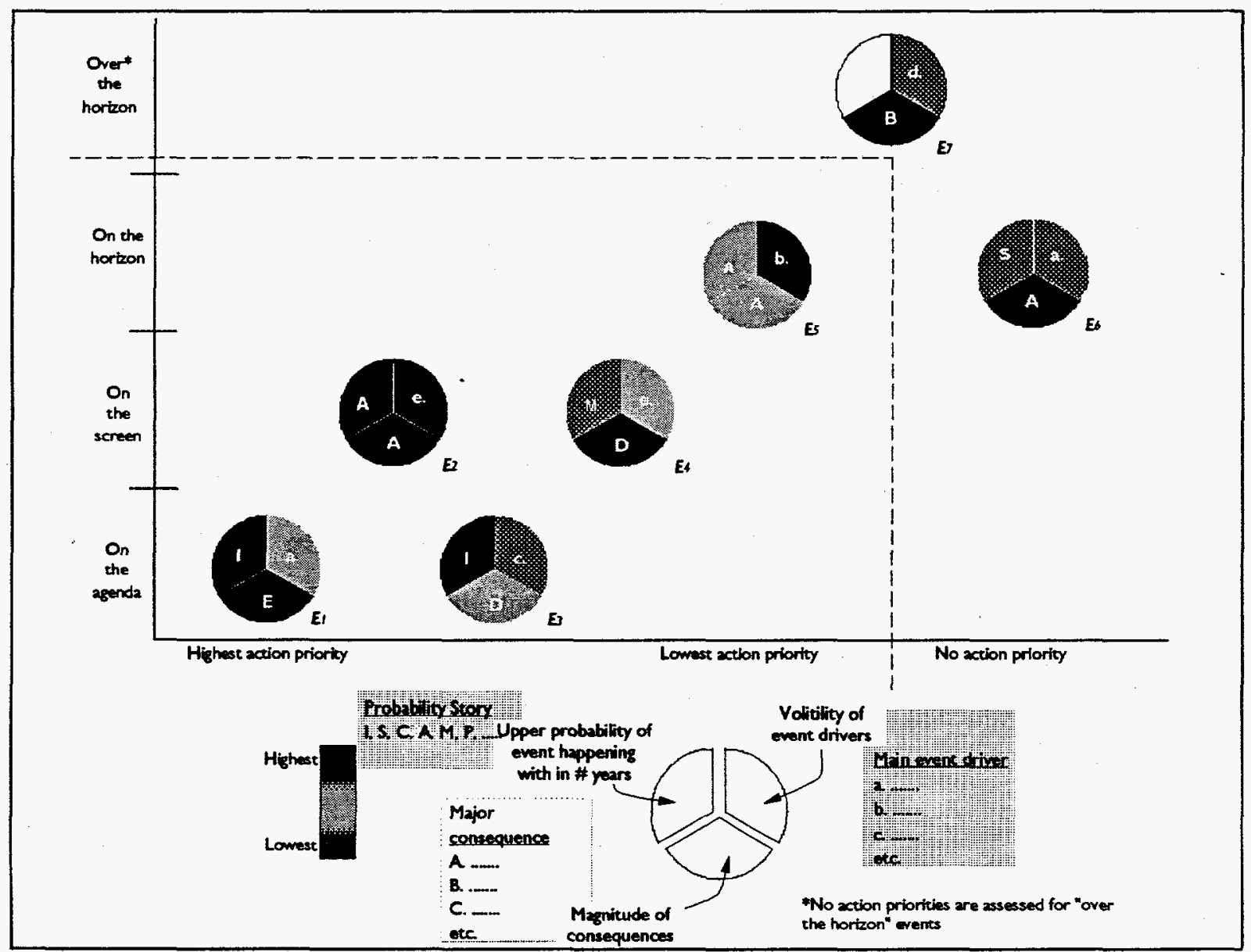

Fig. 6. Tracking status and action priority of potential future environmental regulatory events.

Each circle, or orb, represents a future potential environmental regulatory event that is being tracked. The orbs are arranged on the chart along two axes. Along the $y$-axis, the orbs are 
placed into one of the four tracking categories defined in Section 3.2. Along the $x$-axis, the orbs are ordered according to their action priorities, as calculated using the formulas presented in Section 3.4. One would expect to see a correlation between the two axes, with on the agenda events usually having higher action priorities. However, one would not expect to see a perfect correlation because some on the screen and on the horizon events could hold extreme consequences for the organization, and therefore possess high action priorities, while some on the agenda events may have low action urgencies, and therefore low action priorities for the organization.

Each orb is divided into three parts. The bottom third of the orb contains information about the consequences of the event for the organization. A red color indicates high consequences, yellow medium level consequences, and a green color minimum consequences. The letter in that space indicates the most important type of consequence of the event (e.g., cost, human health). The upper left-hand third of the orb contains probability information. In this case, the color represents the upper cumulative probability of the event occurring within a certain period of time (red is high and green is low), and the letter in that space indicates which probability story is applied to the event. \{Note that probabilities are not assessed for events in the over the horizon category. This is because they are too speculative to even generate probabilities. \} The upper right-hand third of the orb captures the volatility of the drivers influencing the event (red is high and green is low), and the letter indicates what kind of driver has the most influence on the occurrence of the event.

Referring to Figure 6, decision makers would prefer to see completely green orbs: low consequence, and low probability events that are driven by predictable drivers. Decision makers would not prefer to see a sea of red orbs: high consequence and high probability events that are driven by unpredictable drivers. A quick glance at such a chart will inform decision makers about the overall environmental regulatory landscape and decision challenges. As discussed in Section 5, if such a chart were tied to a database system, then one could click on an orb to obtain additional information. For example, if one wanted to begin to view the 


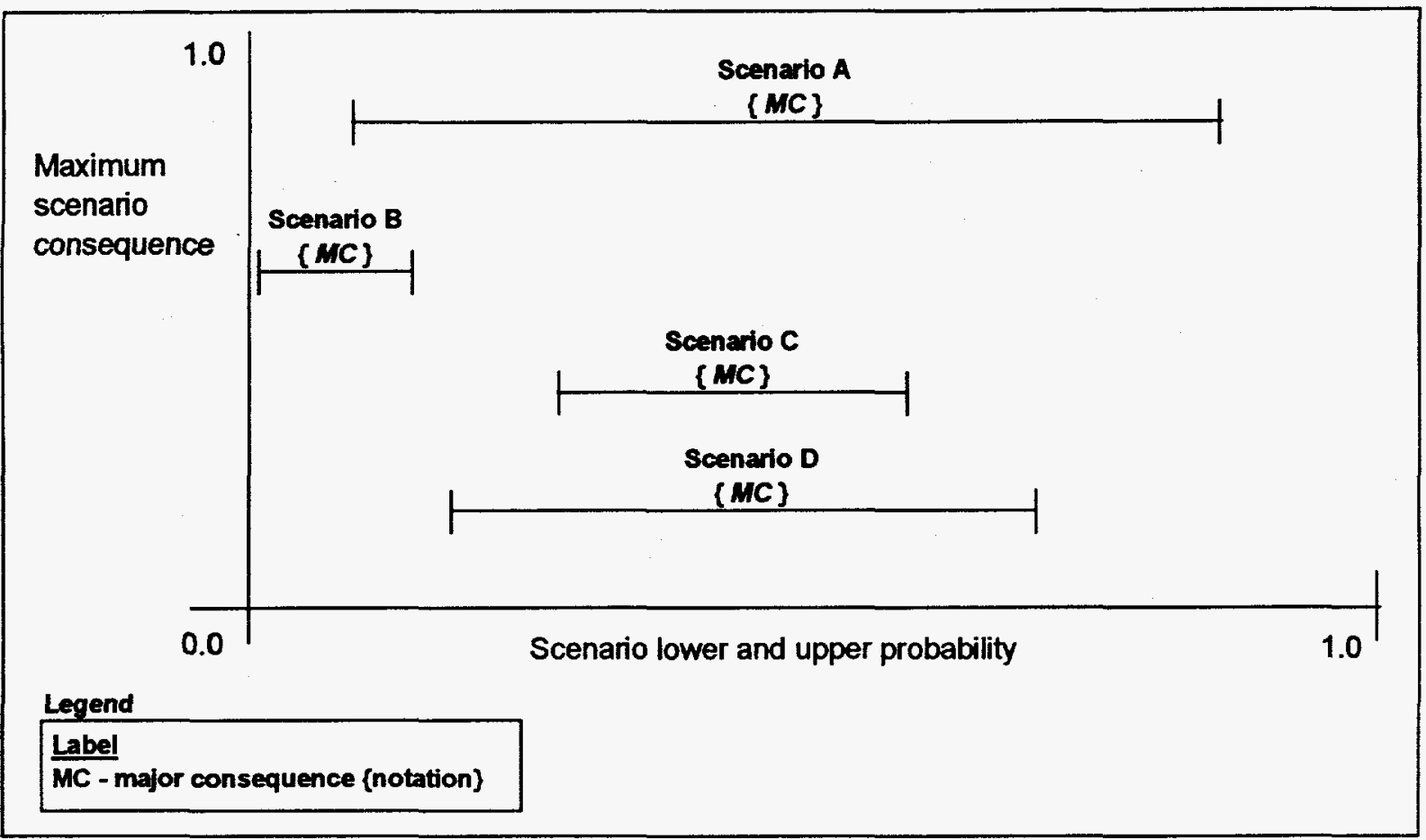

Fig. 7. Current scenarios for a potential future environment regulatory event $E_{j}$.

scenarios associated with an event, one might click on an orb and bring up something like Figure 7. This chart orders scenarios for an event from lowest to highest potential consequence to the organization along the $y$-axis. The $x$-axis indicates the lower and upper probabilities for the scenarios. Additional informative notations can be included within the brackets.

As mentioned in the previous section, the notion of action urgency has different meanings when applied to different decision making contexts within the organization. It may not be possible nor appropriate for the regulatory analysts responsible for tracking potential future environmental regulatory events to specify measures of action urgency for other parts of the organization. On the other hand, ways of summarizing the tracking status of key events are still needed. Figure 8 presents one way of presenting a summary of tracking information to other parts of the organization. Plotted on Figure 8 are the same orbs as shown on Figure 6. The $y$-axis is the same also. Changed is the $x$-axis, which now represents potential 


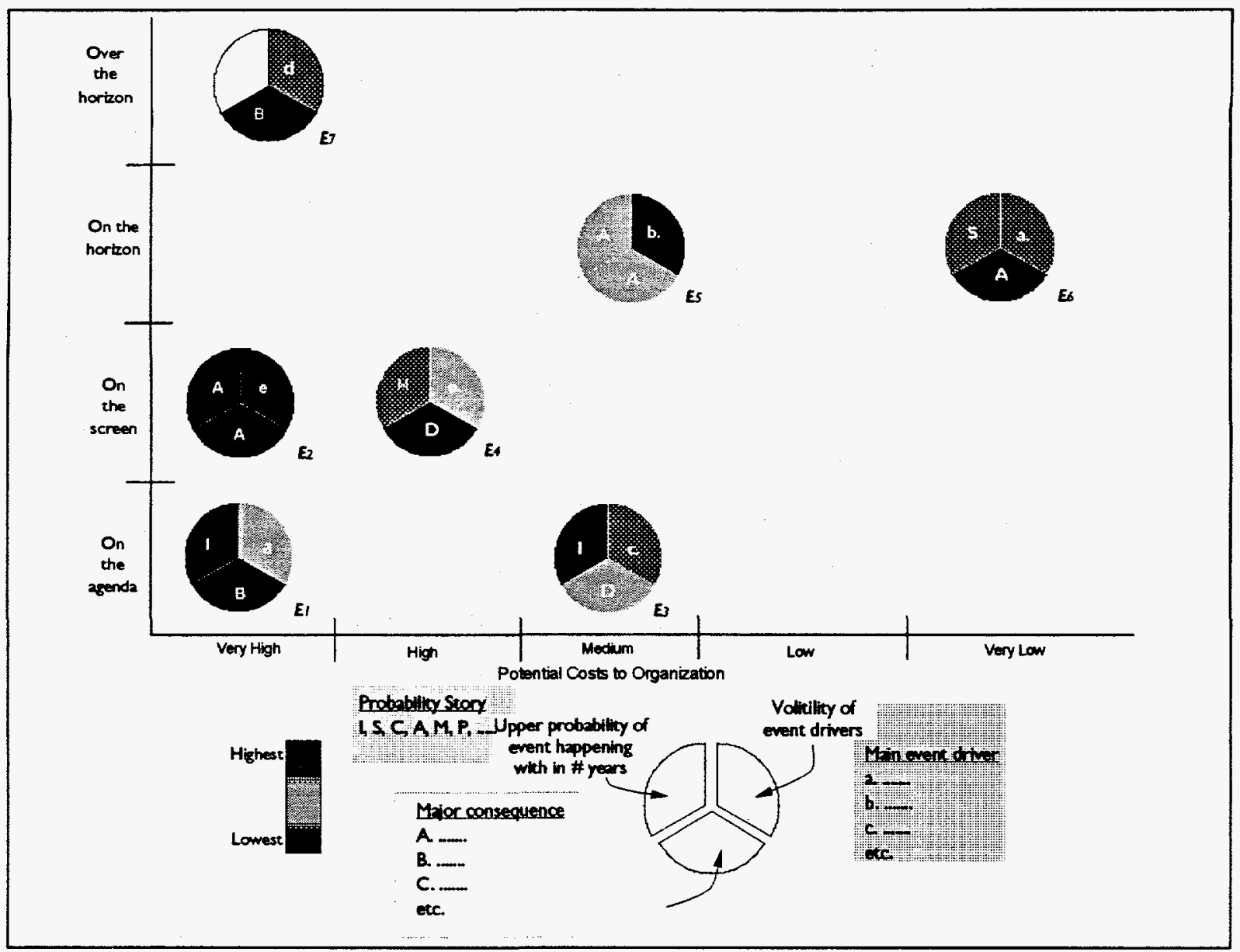

Fig. 8. Tracking status and consequences of potential future environmental regulatory events.

consequences instead of action priorities. Events residing toward the lower left-hand side of the figure still deserve the most attention. People in other parts of the organization can use summaries such as this as a first step toward developing their own action urgency measures and action priorities.

Lastly, the three figures just presented can be revised in numerous manners and complemented by other displays. For example, the orbs can be broken into four parts if additional summary information is desired. Additional displays might address: how orbs have moved and may move from one position to the next over time; different measures of urgency attached to the same event by different parts of the organization; or the tracking status of events. 


\subsection{ASSESSMENT APPROACH STEPS}

Figure 9 illustrates the steps involved in using the assessment approach described above. The overall goal is to fill out the tracking scheme with issues, events, and all the associated

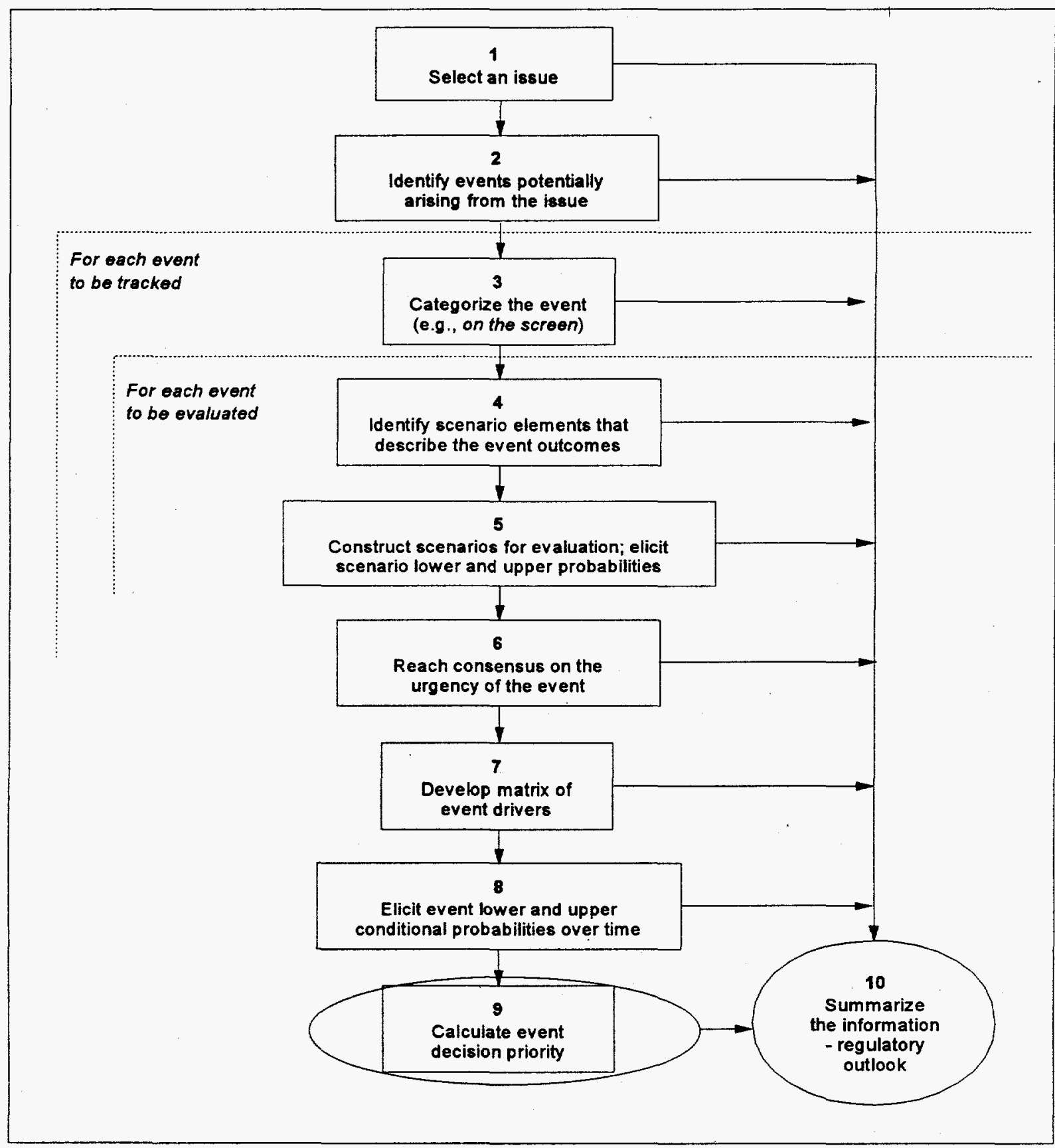

Fig. 9. Assessment approach steps. 
information and calculations. Most of the steps require the time and effort of one or more regulatory analysts and media specialists to complete. In what order the steps are undertaken can affect the efficiency of the process and how well people understand the process.

The first step in the process is to select an issue for discussion. Examples of issues of importance are tropospheric ozone and wastewater discharge. In the second step, for the chosen issue, the goal is to identify events potentially arising from the issue. Step 2 should be approached as a brainstorming exercise in that no contributions people make should be discarded. All ideas for potential events need to be recorded in some fashion for future consideration.

Not all events deserve equal attention, especially during the initial process of building the tracking system. For each event deemed worthy of tracking, the next step, Step 3, is to categorize the event into one of the four tracking categories, over the horizon, on the horizon, on the screen, and on the agenda. At this point in the process, it may be beneficial to expend analytical resources only on a subset of events that appear to be of most importance to the organization. For each of those events, it is recommended that the remaining steps be followed and completed for one event before undertaking the steps for another event.

The fourth step is to identify the scenario elements that describe the event outcomes. This step also has a brainstorming texture, as ideas for scenario elements should not be discarded out of hand. As with all the steps in the assessment approach, there should be opportunities to revisit the scenario elements (even during the same session) to make considered revisions. It may be that future revisions will attempt to cut down the number of elements and the number of values each element can take on in order to simplify the task of keeping track of all the possible scenarios associated with an event. The need for simplification will be first apparent during step 5, which entails constructing a matrix of event scenarios, where each scenario is composed of a unique combination of values for the scenario elements. To begin this process, it is useful to construct a best case scenario, a worst case scenario, and two or three likely 
scenarios. Lower and upper probabilities for each constructed scenario can be elicited during this step. Please note that these five or so scenarios may represent only a small number of potential scenarios, which could run into the hundreds or thousands, given the number of scenario elements and the values they can take on. For example, an event defined by only four elements, where each element can take on only four values, can have 256 scenarios.

Step 6 entails developing the measure of action urgency discussed in Section 3.4. If more than one person is involved in this step, some method of finding a consensus measure will be needed. Step 7 entails developing a matrix of event drivers. For a third time, this exercise involves a degree of brainstorming, because many and possibly obscure drivers could impact the event and no idea should be discarded at this point. In this step, how each driver impacts the probability of the event occurring and the magnitude of the impact need to be assessed. Having the event's drivers fresh in mind will help to complete step 8, which entails eliciting . the lower and upper conditional probabilities of the event occurring over time. It is recommended that a "story" be chosen first to frame the elicitation. Then the elicitation of the probabilities should be undertaken.

Step 9 entails a mechanical application of the equations set out in Section 3.4. These can be automated in a spreadsheet program. Step 10 entails summarizing the information about the event, and all the events, using displays presented in Section 3.5 as appropriate. 


\section{EXAMPLES}

The assessment methodology outlined in Section 3 was tested in two cases of importance to companies in the electric industry. Two separate assessment sessions were held with several regulatory analysts. One session focused on air quality issues. The second session focused on water resource issues.. In each case, several issues and associated events were generated before one issue and one associated event were chosen for in-depth assessment. In the sessions, participation was limited to two or at most three regulatory analysts. In each of the cases, one or two facilitators led the discussions and the assessment process covered most of the day.

The following sections summarize the results of these exercises in a format that can be adopted as the basis for routine assessments. During the exercises themselves, the facilitator(s) kept notes on flip charts, whose pages were taped to walls as they were produced. Substantively, the assessment process followed the first eight steps outlined in Figure 9:

- brainstorming of candidate issues and associated events;

- selecting an issue/event combination for further assessment;

- assigning the chosen event into one of the four tracking categories;

- generating scenario elements and the values they can take;

- constructing several scenarios using the scenario elements and values;

- assessing action urgency associated with the event over a ten to twelve year period;

- generating a list of drivers associated with the event; and

- assessing event probability stories and lower and upper probabilities.

After these sessions, the assessed action urgency measures and event lower and upper probabilities were used to calculate the action priorities, using the equations presented in Section 3.4. 


\subsection{AIR QUALITY}

\section{Candidate Issues/Events}

Issue: Tropospheric Ozone

Events: $\quad$ EPA implements state by state $\mathrm{NO}_{\mathrm{x}}$ emissions budget (CAA Section 110). EPA implements $\mathrm{NO}_{\mathrm{x}}$ reduction requirement using CAA Section 126. Outcome of judicial event related to new standards

Issue: Global Climate Change

Event: Carbon Tax

Issue: Fine Particle Pollution

Event: $\quad$ EPA issues fine particle standard(s)

Issue: Regional Haze

Issue: $\quad$ Air Toxics

2. Selected Issue/Event: Tropospheric Ozone/EPA implements state by state $\mathrm{NO}_{\mathrm{x}}$ emissions budget (CAA Section 110)

3. Event Category: The event is categorized as on the agenda. EPA has been directed to issue the draft regulation within a few months. EPA will have to actively work on implementation after that.

4. Scenario Elements (for Event: EPA implements state by state $\mathrm{NO}_{\mathrm{x}}$ emissions budget (CAA Section 110)): 


\begin{tabular}{|l|l|}
\hline \multicolumn{1}{|c|}{ Element } & \multicolumn{1}{c|}{ Potential Values } \\
\hline 1. Trading & $\begin{array}{l}\text { no trading, intra-company, intrastate, interstate/region, } \\
\text { intersector, banking allowed }\end{array}$ \\
2. Method of allocating & input, output \\
to utilities & \\
3. Episodic controls & allowed, not allowed \\
4. Fuel basis & fuel dependent, fuel independent \\
5. State reaction & uniform, not uniform \\
6. Budget distribution & allocation by source sector contribution, allocation by cost of \\
reduction & control: (a) $\$$ per ton NOx reduction, (b) $\$$ per ozone \\
& reduction \\
7. Emissions cap & yes, no \\
8. Budget & $65 \%, 75 \%, 85 \%$ \\
9. Emissions level in & status quo, higher, lower, redistributed \\
baseline year & included in budget, excluded \\
10. New sources & $2000,2004,2007$ \\
11. Timing &
\end{tabular}

5. Selected Scenarios (for event EPA implements state by state $\mathrm{NO}_{\mathrm{X}}$ emissions budget (CAA Section 110)

\begin{tabular}{|l|c|c|c|}
\hline \multicolumn{1}{|c|}{ Element|Title } & Worst Case & Best Case & Likely Case \\
\hline 1. Trading & no & regional/intersector, & regional, banking \\
& & banking & \\
2. Method & input & output & output \\
3. Episodic & not allowed & allowed & not allowed \\
Controls & & & dependent \\
4. Fuel Basis & independent & dependent & \\
\hline
\end{tabular}




\begin{tabular}{|l|c|c|c|}
\hline \multicolumn{1}{|c|}{ ElementiTitle } & Worst Case & Best Case & Likely Case \\
\hline 5. State Reaction & non-uniform & uniform & uniform \\
6. Budget & cost of control (a) & by source sector & cost of control (b) \\
Distribution & & & \\
7. Emissions Cap & yes & no & no \\
8. Budget & $85 \%$ & $65 \%$ & $75 \%$ \\
Reduction & & & \\
9. Emission Level & higher & lower & status quo \\
10. New Sources & included & excluded & n/a \\
11. Timing & 2000 & 2007 & 2004 \\
Lower Probability & .25 & .10 & .20 \\
Upper Probability & .50 & .20 & .40 \\
\hline
\end{tabular}

6. Action Urgency of Event (for event EPA implements state by state $\mathrm{NO}_{\mathrm{X}}$ emissions budget (CAA Section 110)

\begin{tabular}{|c|c|}
\hline $\begin{array}{c}\text { Years Before Event } \\
\text { Occurs }\end{array}$ & $\begin{array}{c}\text { Level of Urgency } \\
(0.0=\text { min., 1.0= max. })\end{array}$ \\
\hline 1 & 0.90 \\
2 & 0.90 \\
3 & 0.90 \\
4 & 0.90 \\
5 & 0.85 \\
6 & 0.65 \\
7 & 0.35 \\
8 & 0.15 \\
9 & 0.05 \\
\hline
\end{tabular}




\begin{tabular}{|c|c|}
\hline $\begin{array}{c}\text { Years Before Event } \\
\text { Occurs }\end{array}$ & $\begin{array}{c}\text { Level of Urgency } \\
(0.0=\min , \mathbf{1 . 0}=\max .)\end{array}$ \\
10 & 0.0 \\
11 & 0.0 \\
12 & 0.0 \\
\hline
\end{tabular}

7. Event Drivers (for event EPA implements state by state $\mathrm{NO}_{\mathrm{x}}$ emissions budget (CAA Section 110)

\begin{tabular}{|l|c|c|}
\hline \multicolumn{1}{|c|}{ Event Driver } & $\begin{array}{c}\text { Directional Effect on } \\
\text { Probability of Event } \\
\text { Occurring }\end{array}$ & $\begin{array}{c}\text { Influence on } \\
\text { Probability of Event } \\
\text { Occurring }\end{array}$ \\
\hline Environmental Special & increases & high \\
Interest Groups & increases \\
Democrats in White House & increases, decreases \\
State Politics & increases & high \\
EPA Influence on States & increases & high \\
Environmental Conditions & increases & high \\
Public Issue & decreases & low \\
Other Environmental & & low \\
Regulatory Events & increases, decreases & low \\
Science Review in Year & & low \\
2000 & decreases & \\
Utility Lawsuits & &
\end{tabular}


8. Probability of Event Occurring (for event EPA implements state by state $\mathrm{NO}_{\mathrm{x}}$ emissions budget (CAA Section 110)

\begin{tabular}{|c|c|c|}
\hline Year & Lower Probability & Upper Probability \\
\hline 1997 & 0.0 & 0.0 \\
1998 & 0.0 & 0.0 \\
1999 & 0.0 & 0.0 \\
2000 & 0.10 & 0.20 \\
2001 & 0.15 & 0.25 \\
2002 & 0.15 & 0.25 \\
2003 & 0.20 & 0.30 \\
2004 & 0.30 & 0.60 \\
2005 & 0.40 & 0.65 \\
2006 & 0.45 & 0.70 \\
2007 & 0.50 & 0.90 \\
2008 & 0.50 & 0.90 \\
\hline
\end{tabular}

9. Calculated Action Priority: The calculated Action Priority $\left(A^{*}\right)$ is 0.52 over a 12 year period. \{Note: for reference, the maximum $A^{*}$ over this period would be 1.0.\} The lower expected action urgency is 0.36 and the upper expected action urgency is 0.54. $A^{*}$ is calculated using the equation (9) in Section 3.4, where $\alpha$ has been set at 0.1 (very high aversion to risk) for this example.

10. Summary of Event: In reference to Figure 6 in Section 3.5, the event $E P A$ implements state by state $\mathrm{NO}_{X}$ emissions budget (CAA Section 110) would be placed in the on the agenda category on the $y$-axis and would be placed somewhat to the right of the middle of the $x$-axis with respect to Action Priority. The magnitude of the consequences would have a red shading, with the major consequence being economic. The upper probability of the event happening within ten years would also have a red 
shading. The volatility of the event drivers would have a yellow to light green shading, indicating a mid-level of volatility, with the major event driver being environmental special interest groups.

\subsection{WATER RESOURCES}

\section{Candidate Issues/Events}

Issue: Will power generators be required to assess, modify, replace or otherwise mitigate its cooling water intake?

Event: $\quad$ EPA develops new Section 316(b) regulations

2. Selected Issue/Event: EPA develops new Section $316(\mathrm{~b})$ regulations

3. Event Category: The event is categorized as on the agenda. EPA is under a court ordered consent degree to issue new intake regulations, and the court has indicated a time frame for when new regulations will be issued.

4. Scenario Elements (for Event: EPA develops new Section 316(b) regulations):

\section{Definition of Adverse Impact}

single fish

non-maintenance of balanced indigenous population

non-maintenance of maximum sustainable yield

$\geq 10 \%$ reduction in standing stock

biocriteria rating below good

irreversible damage

less than significant and substantial harm 
$\leq 1000$ fish

2. Definition of Best Technology Available (BTA)

closed loop cooling

definition based upon intake flow and environmental setting (permit by rule)

permittee defines based upon site parameters (plant/site specific)

regulator defines based upon site parameters (plant/site specific)

\section{Cost/Benefit Approach}

linked to worth of plant

cost/benefit is not allowed

1:1 ratio of improvement cost to environmental benefit

employs the "not wholly disproportionate" approach

\section{Allowance of non-standard mitigation}

not allowed

$0-50 \%$ mitigation allowed

$51-100 \%$ mitigation allowed

permittee proposes mitigation

permitting authority dictates mitigation to be performed

5. Selected Scenarios ( for event EPA develops new Section 316(b) regulations)

\begin{tabular}{|l|l|l|l|}
\hline \multicolumn{1}{|c|}{ Element|Title } & \multicolumn{1}{c|}{ Worst Case } & \multicolumn{1}{c|}{ Best Case } & Likely Case \\
\hline 1. Adverse & single fish & no irreversible & single fish \\
Impact & & damage & \\
2. BTA & closed loop & plant/site specific & plant/site specific \\
& & defined by permittee & defined by permittee \\
\hline
\end{tabular}




\begin{tabular}{|l|l|ll|}
\hline \multicolumn{1}{|c|}{ Element/Title } & \multicolumn{1}{c|}{ Worst Case } & \multicolumn{1}{c|}{ Best Case } & \multicolumn{1}{c|}{ Likely Case } \\
\hline $\begin{array}{l}\text { 3. Cost/benefit } \\
\text { Approach }\end{array}$ & not allowed & linked to worth of & $\begin{array}{l}\text { costs are wholly } \\
\text { disproportionate to } \\
\text { benefits }\end{array}$ \\
4. Mitigation & not allowed & $100 \%$ permittee & 5 to $100 \%$ \\
& & proposes & \\
Lower Probability & .2 & .2 & .4 \\
Upper Probability & .5 & .6 & .8 \\
\hline
\end{tabular}

6. Action Urgency of Event (for event EPA develops new Section 316(b) regulations)

\begin{tabular}{|c|c|}
\hline $\begin{array}{c}\text { Years Before } \\
\text { Event Occurs }\end{array}$ & $\begin{array}{c}\text { Level of Urgency } \\
(\mathbf{0 . 0}=\mathbf{m i n} . \mathbf{1 . 0}=\mathbf{m a x} .)\end{array}$ \\
\hline 1 & 1.0 \\
2 & 1.0 \\
3 & 1.0 \\
4 & 1.0 \\
5 & 0.2 \\
6 & 0 \\
7 & 0 \\
8 & 0 \\
9 & 0 \\
10 & 0 \\
11 & 0 \\
12 & 0 \\
\hline
\end{tabular}


7. Event Drivers (for event EPA implements new Section 316(b) regulations)

\begin{tabular}{|l|c|c|}
\hline \multicolumn{1}{|c|}{ Event Driver } & $\begin{array}{c}\text { Directional Effect on } \\
\text { Probability of Event } \\
\text { Occurring }\end{array}$ & $\begin{array}{c}\text { Influence on Probability } \\
\text { of Event Occurring }\end{array}$ \\
\hline River Keepers & increases & high \\
Revision of the Clean Water Act & decreases & low \\
Environmental Disaster & increases & low \\
Technology companies & increases & low-moderate \\
Natural resource management & increases & low \\
agencies & & high \\
Environmental interest groups & increases & moderate \\
Cumulative environmental impact & increases & \\
\hline
\end{tabular}

8. Probability of Event Occurring (for event EPA develops new Section 316(b) regulations)

\begin{tabular}{|l|c|c|}
\hline Year & Lower Probability & Upper Probability \\
\hline 1997 & 0.0 & 0.0 \\
1998 & 0.0 & 0.0 \\
1999 & 0.0 & 0.0 \\
2000 & 0.0 & 0.4 \\
2001 & 0.9 & 1.0 \\
2002 & 0.9 & 1.0 \\
2003 & 0.9 & 1.0 \\
2004 & 0.9 & 1.0 \\
2005 & 0.9 & 1.0 \\
2006 & 0.9 & 1.0 \\
\hline
\end{tabular}




\begin{tabular}{|c|c|c|}
\hline Year & Lower Probability & Upper Probability \\
\hline 2007 & 0.0 & 0.4 \\
2008 & 0.0 & 0.4 \\
\hline
\end{tabular}

9. Calculated Action Priority: The calculated Action Priority $\left(A^{*}\right)$ is 0.198 , over a 12 year period. \{Note: for reference, the maximum $A^{*}$ over this period would be 1.0.$\}$ The lower expected urgency is 0.18 and the upper expected urgency is $0.20 . A^{*}$ is calculated using equation (9) in Section 3.4, where $\alpha$ has been set at 0.1 (very high aversion to risk) for this example. Note that one year from now, the $A^{\bullet}$ for this event will rise dramatically.

10. Summary of Event: In reference to Figure 6 in Section 3.5, the event EPA develops new Section 316(b) regulations would be placed in the on the agenda category on the $y$-axis and would be placed on the far right-side of the $x$-axis with respect to $A^{*}$. The magnitude of the consequences would have a red shading, with the major consequence being economic. The upper probability of the event happening within ten years would also have a red shading. The volatility of the event drivers would have a yellow to light green shading, indicating a mid-level of volatility, with the major event driver being environmental special interest groups. 


\section{IMPLEMENTATION ISSUES AND CONCLUSIONS}

\subsection{IMPLEMENTATION ISSUES}

Over the course of this project, several observations have been made regarding challenges to organizations in implementing the methods described above. These observations were distilled from general discussions about the key concepts outlined in Section 2, questions and concerns about the methods presented in Section 3, and interactions during the elicitation process that lead to the examples reported in Section 4. With respect to implementing the methodology, difficulties were observed associated with: problem structuring; elicitation of drivers; uncertainty elicitation; urgency curves; and finding consensus. To conclude this subsection, some observations are made about how to implement the methodology in an organization.

\section{Problem structuring}

As discussed in Section 4, the first task is to structure the problem (i.e., to make very clear the definition of the event and its scenario elements and scenario element values). Three observations are made about problem structuring. First, it takes time and effort to clearly specify the event. In the first two examples presented in Section 4, participants even changed the event specification late into the elicitation process, making the event specification more precise. Obtaining a precise event description takes considerable work and participants need to understand that it is acceptable to iterate and revise the event specification as needed.

Similarly, as the elicitation progressed, revisions and additions were made to the scenario elements and their values. It is a challenge to identify all of the elements that contribute to variation in potential scenarios that follow from the occurrence of the event. Participants need to understand that it is acceptable to revise scenario elements over time, as the result of beneficial reflection. 
A third observation is related to construction of the scenarios. There was a tendency of the participants to focus on the worst case scenario. This is acceptable as long as it is kept in mind that the worst case scenario may not in fact be very probable and is only one in a potentially very large set of scenarios. Forcing participants to consider all potential outcomes of the event without regard for either the likelihood of an outcome or its desirability opens up the scenario space to a greater number of possibilities than is typically considered. The process also leads to better communication about the event and its possible outcomes.

Ideally, part of the problem structuring task can be accomplished by using a facilitator, and part by using a computer. The facilitator could work with one or two domain experts to establish the event and the elements that result in variation in the scenarios. Once elements are established, they could be input to a computer program to generate all possible scenarios. These would be reviewed by the domain experts and the facilitator to identify scenarios that are logical impossibilities. These would be excluded from further analyses. The remaining scenarios would be established as a database for the rest of the elicitation and for future tracking and assessment.

\section{Elicitation of drivers}

It was observed that elicitation of the drivers can be done with more structure and better linking to uncertainties. For example, the drivers could be elicited individually without regard for their impact on the event/scenario. Care should be taken to include all possible drivers and to work through the list of drivers carefully to insure that they are made as specific as possible.

After the drivers have been elicited, then the direction of impact of the each driver on the event should be elicited. For example, does the presence of the driver increase or decrease the likelihood of the event? These directionalities should be noted for each driver. Also for each driver, any time dependencies should be elicited. For example, does the driver operate 
throughout the entire time frame for the event, or does it operate only at specific time periods, such as political elections? Then, the influence of each driver on the event should be elicited. This can be done using either a rating scale technique, or a simple categorical judgment of low, medium and high.

\section{Probability/uncertainty elicitation}

Ideally, eliciting the lower and upper conditional probabilities for events would be done on a computer. A stand-alone PC module could be developed for this purpose. In the interim, however, a workable substitute can be created by eliciting upper and lower conditional probabilities for each year in the time horizon of the event.

First, it is important to establish the time horizon. Is this in terms of years? decades? The elicitation of upper and lower conditional probabilities can be done either directly, or by eliciting point probabilities and then establishing reliabilities in terms of ranges around the point probabilities. The ranges are taken as the upper and lower conditional probabilities. This exercise can be done using a spreadsheet model on a computer, or it can be done using a matrix on a whiteboard with a facilitator. The advantage of the spreadsheet is that it can be linked to a graphics program to display the distribution directly. This is more difficult using a hardcopy approach.

The drivers, their directions of impact, time dependencies and influence ratings should all be available in a single display as a part of choosing a probability story and assessing the upper and lower conditional probabilities for the event. The individual(s) providing the conditional probabilities should be allowed to change their conditional probabilities to reflect their belief in the occurrence of the event throughout the time horizon. In a sophisticated computer-based elicitation, point probabilities would be used to establish the initial curves. A smoothing function would be applied to the probability values (i.e., both lower and upper). The user 
would then modify the shape of the curve by altering its form directly rather than through the point probabilities.

\section{Action Urgency Curves}

This aspect of the elicitation seemed difficult for the participants. A stumbling block here is the concept of bringing the issue to the attention of decision makers, and what that really means in terms of how the organization actually operates. There are a couple of things that might improve participants understanding of the measure of action urgency for an event. First, some time needs to be dedicated to modeling how the organization makes decisions and how regulatory outlook would be integrated into the decision-making structure of the organization. At present, events are mostly dealt with when they are on the agenda. How would events on the horizon be dealt with? What aspects of the organization's decision making would want to be informed about such events?

A second problem was the characterization of the slope portion of action urgency curve. This was characterized to participants as cost of false alarms. A better definition may be in terms of degree of discretion in undertaking action in reaction to potential events (as set out in Section 3.4). Participants in the example exercises tended to see this part of the curve in qualitative terms. Additional work needs to be made on the example curves set out in Figure 5 to better align them with mental models of regulatory analysts.

\section{Finding Consensus}

The assessment process described herein can be implemented by any number of people in any number of ways. An issue that comes up when more than one person is contributing to any part of the process is how to deal with disagreements. Put in another way, the question becomes how to find consensus among the participants. It is beneficial to have an answer to 
this question before the process is implemented so that all participants are aware of the ground rules.

Disagreements can arise in many areas of the process: how exactly to specify the event; where to categorize the event (e.g., on the screen or on the agenda?); about the number and nature of the scenario elements; about the specification of the action urgency curve; about the number and nature of the event drivers; about the lower and upper conditional probabilities related to the occurrence of the event; about the probabilities of the scenarios; and the specification of the risk aversion. Factors that influence the potential level of disagreement include: the number of people involved; the personalities of the people involved; the knowledge level of the people involved; the position in the organization of the people involved; the experience with the assessment process of the people involved; the skills of the facilitator; the time allocated for implementing the process for an event; the complexity of the event; and uncertainties surrounding the event.

In a perfect world, the preferred approach to bridging disagreements is to continue discussions until everyone in the process comes to agreement. A facilitator can lead such extended discussions. A Delphi approach can be implemented where participants provide initial assessments, the initial assessments are shared with the group and discussed, a second round of assessments are provided and discussed, until a consensus is reached. This approach is valid for both qualitative assessments (e.g., event drivers) and quantitative assessments (e.g., event probabilities).

With respect to quantitative assessments of event and scenario probabilities, one can also use mathematical techniques to find consensus. Basically, one has two options with respect to two issues. The first issue concerns how to manage ranges in assessed probabilities and the options are to average the probabilities in some manner or choose the lowest lower probabilities and the highest upper probabilities (i.e., choose a lower and upper envelop of probabilities). The second issue concerns whether to assign weights to the influence each participant has in the 
assessment process, with the two options on whether to give people equal weights or give some people more weight than others.

An insight that arose during the assessment process exercises is that in certain instances it is not advisable to average probabilities of events. The most important case is when people involved in the assessment process specify two or more different probability stories, as shown in Figure 3. Averaging probabilities from different stories will ruin the coherence of any one story and will result in lower and upper probabilities that do not represent any story at all. In such cases, it is recommended that the consensus position is to use the probability story with the lowest lower probabilities and the probability story with the highest upper probabilities. This is in essence using the largest envelope approach (i.e., an approach that uses the lowest set of lower probabilities and the highest set of upper probabilities.

One can also argue that using an envelope approach is appropriate for dealing with disagreements about scenario probabilities. This argument is based on the assertion that disagreement on the probabilities arises from fundamental uncertainty about which scenario will become true and the envelop approach (i.e., using the lowest lower probabilities and the highest upper probabilities) most directly captures this fundamental uncertainty.

The counter arguments to the envelope approach are that it is too conservative and that fringe opinions can cause more spread in the numbers than is reflected by the larger group, most of whom may be in close agreement. Weighting approaches would yield small ranges in both the event and scenario probabilities.

There are no hard and fast rules regarding mathematical consensus and the organization is encouraged to test various approaches. However, our recommendation is to adopt the envelope approach for the following reasons: 
- it is the only appropriate approach to deal with diversity in event probabilities arising from the specification of two or more different event probability stories;

- it accurately captures the disagreement in the group;

- one does not have to deal with the thorny issue of assigning different weights to different people in the process; and

- decisions about how conservative the organization should be can be made with respect to specifying the $\alpha$ value in Equation 9 (see Section 3.4).

There are fewer options to weigh with respect to qualitative assessments simply because there are no mathematical methods available. In some cases, a consensus viewpoint would be to be more inclusive rather than exclusive. For example, one can include more rather than fewer event drivers in one's list and more scenario elements rather than fewer. One can implement a voting scheme to choose which category to place an event. It may be up to the facilitator or assessment leader to resolve disputes about the event specification and/or to have ultimate responsibility for this task.

It must be stressed that every event will be revisited on a regular basis. As people become more familiar with the event, it is natural to foresee that many aspects of the event will be revised, from its specification to its probabilities. So, while consensus is important, the lack of consensus is not a fatal problem given that revisions can be made and given that reasons for disagreement can be catalogued and be a source of insight into the event itself.

\section{Institutionalization of process}

To implement the methodology presented herein for assessing potential future environmental regulatory events, an organization needs to institutionalize the process over time. One way of doing this is to identify a core set of assessment leaders who are prepared to look farther out on the time horizon than has typically been the case for the organization to date. Each assessment leader should be trained not only in the methods presented above, but also more 
generally in the need to take the longer view. These individuals will be the ones to maintain the assessment program and to work with staff assigned to categories of issues and events.

The assessment leaders should engage in ongoing interaction to support each other and to use and coordinate outside resources, such as the team that developed the methodology. The development team should stay in the loop as an ongoing consultant to the process. To initiate this process, a set of assessment leaders could be identified. They would receive a one-day workshop on the assessment methodology, including case studies from other areas that illustrate the value of future thinking. These individuals would be "gatekeepers" of the process and would be familiar not only with their own issues and events, but with other issues and events for which the assessment methodology is appropriate. They would be the individuals who would brief the organization's management on events as they change position on Figure 6.

This would be followed by individual workshops for each assessment leader in which an event is selected and completely modeled (as illustrated in the examples in Section 4). The results of each event workshop would be documented and prepared in a workbook form for the assessment leader to review. A second half-day workshop a month later would take each assessment leader through a review and update of the event model. Thereafter, sessions would be held every quarter to review and update the model of the event. This review and update would extend for three to five years. During this period, the event model would be expanded, tracked, and computerized. The assessment leader would bring in one or more staff members to become familiar with the event and its tracking. By the end of the three to five year period, the event would be thoroughly modeled and a tracking program would be in place. The key to this process is ongoing involvement with an outside facilitator(s) to maintain a consistent updating and refining of the event model. 


\subsection{POTENTIAL FUTURE IMPROVEMENTS TO ASSESSMENT METHODOLOGY}

The methodology presented above does not exhaust all possible sophistications of the assessment process. For example, the methodology could be extended to:

- formally track event drivers;

- assess lower and upper probabilities on event drivers;

- calculate lower and upper conditional probabilities of events based on the lower and upper probabilities of their event drivers;

- formally and quantitatively assess the magnitude of potential consequences of each scenario associated with each potential event; and

- calculate lower and upper expected consequences of events based on event and scenario probabilities and magnitudes of potential consequences.

Better tools can be developed to assist regulatory analysts in assessing probabilities and measures of action urgencies. For example, several examples of probabilities tied to common knowledge can be developed to help guide regulatory analysts in assessing proper probability magnitudes. The same can be done for measures of action urgency. Computerizing the assessment process could help tremendously, as the computer could allow analysts to draw figures or revise given probability and urgency figures. The computer could also help enforce guidelines on probabilities and urgencies (e.g., the sum of the lower probabilities on scenarios associated with an event have to sum to $\leq 1.0$ ). The computer can also help facilitate the input of assessments into the database, and implement Delphi and other consensus processes.

All of these improvements need to be weighed against their costs. Developing computer code takes time and money. Such investments are more worthwhile the more users one has for the software and the more valuable the information that will emerge from the system. The technical improvements listed above also would take more time and energy, and require a 
corresponding intense training of the responsible staff, which may or may not be cost efficient. As pointed out below, a major challenge is knowing where to circumscribe one's efforts in this area.

\subsection{CONCLUDING THOUGHTS}

Assessment activities are only limited by one's ability to understand and integrate all potentially relevant factors. From a meta-physical perspective, one can argue that every aspect of social reality is related in some way to every other aspect of social reality. Thus, in some sense, an ideal assessment system would not only track every imaginable potential future environmental regulatory event but also every possible event driver, secondary drivers, tertiary drivers, ad infinitum. Every conceivable information source would be tapped for tracking and. assessment information. All scenario elements would be specified as would all possible values for the scenario elements. All of the tens of thousand potential scenarios would be tracked and assessed. As many people as possible would be involved in the assessment activities, in order to draw upon the organization's knowledge base and to infuse as many people as possible with common beliefs about potential future environmental regulatory events. Only brute force, time consuming consensus processes would be used.

No organization can or would want to come close to implementing the ideal. Judgment is needed to circumscribe what will be tracked, what information will be collected, and who will be involved in doing what. The tricky part in implementing this assessment methodology is in balancing investments made in tracking events that are almost certain to occur versus imagining and implementing the ability to track highly speculative events. The latter cannot be sacrificed without harming the organization's ability to act proactively and creatively.

As part of implementing this assessment methodology, a formal evaluation methodology should also be developed and implemented. This methodology will evaluate how well the 
organization is implementing the assessment methodology, determine the efficacy of manpower devoted to assessment, and measure the reliability and validity of all information generated during assessment processes. 


\subsection{ACKNOWLEDGMENTS}

This project was co-funded by the Tennessee Valley Authority through the Joint Institute for Energy and Environment and by the National Center for Environmental Decision-making Research. We wish to thank several people at the Tennessee Valley Authority for their participation in this project. Abe Loudermilk managed this project for TVA and, along with Jon Loney, provided the vision for this project. We thank several TVA regulatory analysts for their time, and patience in participating in discussions and the three example exercises, including: Jim Wright, Lynn Brown, Gil Stauffer, Bill Pitman, Ira Silverberg, and Lee Graser. We thank Sam Carnes for review comments. Lastly, we wish to thank Sheila Moore and Connie Steelman for preparing innovative graphics for this project. 
APPENDIX A. EVENT TRACKING DATABASE DEFINITIONS 



\section{APPENDIX A. EVENT TRACKING DATABASE DEFINITIONS}

It is recommended that organizations build a computer database to assist in the tracking of events and their associated information. Each record in the database would correspond to one event. This appendix outlines what data each record might contain. In the main body of this report, it is mentioned on several occasions that different departments within an organization may place different action urgencies on the same events depending on their responsibilities within the organization (e.g., R\&D versus system operation). To handle this within a database application, the organization might consider implementing an object-oriented database system, where events are the main objects. This approach allows flexibility in associating many different data items with main objects, such as different action urgencies from different departments.

Action Priority: A function of the measure of action urgency, the lower and upper probabilities of the event occurring over time and the measure of risk aversion. Values range between 0.0 and 1.0 .

Action Urgency: A measure of how urgent it is to act in response to a potential future potential environmental regulatory event. The values for action urgency range from 0.0 to 1.0 and are specified over $n$ years. Therefore, the database needs to hold $n$ values of action urgency.

Consequences to the Organization of Scenarios: Description of the anticipated business, public, and environmental consequences of each scenario.

Degree of Organization's Ability to Influence the Event: Specified on a range from low to high. 
Driver(s): Influence events to occur or not to occur. Examples include: regulation, science, litigation, politics, industry, non-governmental organizations (NGOs), risk/science, economics, technology, and public pressure. Associated with each driver is the direction it influences the probability of the event occurring (increases or decreases) and the magnitude of its influence (specified on a range from low to high). The volatility of each driver can also be tracked and specified on a range from low to high.

Event: Something which occurs and comes into being. The database would hold the name of the event and indicate whether it is a legislative, regulatory or judicial event.

Event Category: The database would hold for each event one of the following four tracking categories:

\section{On the Agenda}

Decisions about these events may be on the calendar for decision-making bodies. Examples include:

- regulatory agency formulates or evaluates policy options or recommendations that will become proposed regulations,

- congressional legislation is introduced in either the House or Senate, and

- Supreme Court reviews case or Federal or State Appellate Court is scheduled to hear case.

\section{On the Screen}

Events are receiving much attention form legislators, regulators and others.

Examples of on the screen events and scenarios include: research results, findings, conclusions, demonstrations articulated in risk assessments, literature reviews, or data. 


\section{On the Horizon}

Events have a stronger chance of occurring and are receiving increased attention. Examples of on the horizon events include:

- initiation of studies, formation of advisory groups or task forces, discussions at conferences, articles published in practitioner policy and science literature.

\section{Over the Horizon}

Events having a glimmer of possibility.

- Primarily discussed in futurists literature.

Issue: Matters of importance to the organization. The database would include the name of the issue that the event is associated with.

Probabilities of Occurrence Over Time: The database would hold the lower and upper conditional probabilities of the event. The conditional probabilities range from 0.0 to 1.0. The record would hold $2 \times \mathrm{N}$ numbers. The database should also contain the probability story used to guide the elicitation of the conditional probabilities.

Probabilities of Scenarios: Represent uncertainties associated with a scenario. A lower and probability for each scenario is needed in the database.

Risk Aversion: A number between 0.0 and 1.0 that relates to how risk averse the organizations behavior vis-á-vis the event should be. This number can be different for different events.

Scenario Elements: These are characteristics of the event that describe the possible outcomes of the event. The database needs to hold the name of each element and the names of each value the element can take on.

$$
\text { A - } 5
$$


Scenarios: Represent potential outcomes, or stories associated with events. The database may need to hold hundreds of potential scenarios for each event.

Sources of Intelligence about the Event: Reference sources and organizations that should be checked to maintain tracking of the event.

When to Reassess the Status of an Event: Based on the information collected from the intelligence sources, a prediction of when the status of an event is due for reevaluation. The database would contain a month and year for when the status of the event needs to be reevaluated.

Who is responsible: The database should contain the name of the person primarily responsible for tracking the event. 
APPENDIX B. MATHEMATICAL NOTES 


\section{APPENDIX B. MATHEMATICAL NOTES}

In what follows, time is measured in years, although any other unit of time may be used with no changes in the formulation. Planners are assumed to be engaged in the analytical exercise below at the beginning of year 1 . At that point in time, a certain legislative or regulatory event of interest to the planners' organization has not yet materialized. They are uncertain about when the event in question will materialize, but for each of the possible years $j=1,2, \ldots n$, they can assess a nonnegative number $u(j)$ that measures, in some sense, the urgency of acting now if they were certain that this event would materialize sometime during year $j$.

\section{PROBABILISTIC ANALYSIS}

In the usual probabilistic analysis, one would introduce a random variable $Y$ taking as possible values the years in which the event might materialize, find the probability density function ( $p d f) f$ of $Y$, where

$$
f(j)=P(Y=j)=\text { the probability that the event will materialize in year } j
$$

and then calculate the "expected action urgency" $E(U)$, where $U$ is the random variable $u(Y)$, by the familiar formula

$$
E(U)=\sum_{j=1}^{n} u(j) f(j)
$$

It may be easier for the planners to assess the cumulative distribution function $(c d f) F$ of $Y$, given by

$$
\begin{gathered}
F(j)=P(Y \leq j)= \\
\text { materialize during or prior to year } j \text {, }
\end{gathered}
$$


rather than the $p d f$. If this is done, then one uses instead of (B.2) the equivalent formula

$$
E(U)=u(1) F(1)+\sum_{j=2}^{n} u(j)(F(j)-F(j-1)),
$$

which follows from (B.2) and the fact that $f(I)=F(1)$ and $f(j)=F(j)-F(j-1)$ if $j \geq 2$.

Even assessing the $c d f$ can be difficult, however. An alternative is to assess the socalled "hazard function" $G$ defined for all $j \geq 1$ by

$$
\begin{aligned}
G(j)= & P(Y \leq j \mid Y>j-1)=\text { the probability that the event materializes in } \\
& \text { year } j \text { if it has not yet materialized by the end of year } j-1 .
\end{aligned}
$$

In particular,

$$
G(1)=P(Y \leq 1 \mid Y>0)=P(Y \leq 1)=F(1)
$$

and for $j \geq 2$.

$$
G(j)=\frac{P(j-1<Y \leq j)}{P(Y>j-1)}=\frac{F(j)-F(j-1)}{1-F(j-1)}
$$

If planners assess $G$ rather than $F$, they can recover $F$ from $G$ using the recursive formula

$$
\begin{aligned}
&\left(1^{\circ}\right) F(1)=G(1), \text { and } \\
&\left(2^{\circ}\right)F(j)=F(j-1))+G(j)[1-F(j-1)], \\
& \text { for } j \geq 2,
\end{aligned}
$$

and then calculate $E(U)$ by formula (B.4). 
Typically, planners will be tracking a number of events $e_{1}, e_{2}, \ldots$ They will calculate the expected action urgency $E\left(U_{i}\right)$ associated with each event $e_{i}$ and prioritize action on these events according to the magnitudes of their expected action urgencies.

Note 1.1. In the above discussion it was implicit that the event in question was certain to materialize during one of the $n$ years under consideration. Hence $F(n)=f(I)+\ldots+f(n)=1$ or, stated equivalently in terms of the hazard functions, $G(n)=1$. But this assumption is not necessary in order to use formula (B.4) for $E(U)$. If planners think that there is a positive probability that the event in question will never materialize (but that if it materializes it will do so by the end of year $n$ ), whence $F(n)<1$, they can simply extend the time frame to include year $n+1$ and engage in the (harmless) fiction that $F(n+1)=1$ by setting $u(n+I)=0$. (In effect, never materializing is assimilated to materializing at a time such that there is no urgency now, were the event to materialize at that time.) One then modifies (B.4) by replacing $n$ by $n+1$. But since $u(n+I)=0$ the modified formula is identical to (B.4). In short, (B.4) can be used regardless of whether the event is certain to materialize within $n$ years $(F(n)=G(n)=1)$ or whether there is a positive probability that it never materializes $(F(n)<1, G(n)<1)$.

\section{IMPRECISE PROBABILISTIC ANALYSIS}

If planners are confident in their ability to assess the probabilities required in above analysis, they should by all means pursue that analysis. But it is often the case that individuals lack the information required to ground such an analysis. In such cases they may find it useful to pursue an imprecise probabilistic analysis, i.e., an analysis employing lower and upper probabilities $\underline{P}$ and $\bar{P}$. 
Associated with these imprecise probabilities are the lower and upper $c d f \mathrm{~s} E$ and $\bar{F}$ of $Y$, defined respectively by

$$
\begin{gathered}
E(j)=\underline{P}(Y \leq j), \text { and } \\
\bar{F}(j)=\bar{P}(Y \leq j) .
\end{gathered}
$$

Corresponding to formula (B.4) for $E(U)$, one gets the following formulas for the "lower expected action urgency" $\underline{E}(U)$ and the "upper expected action urgency $\bar{E}(U)$

$$
\begin{aligned}
& \underline{E}(U)=u(1) \underline{E}(1)+\sum_{j=2}^{n} u(j)(\underline{E}(j)-\underline{E}(j-1)) \\
& \bar{E}(U)=u(1) \bar{F}(1)+\sum_{j=2}^{n} u(j)(\bar{F}(j)-\bar{F}(j-1))
\end{aligned}
$$

Note 2.1. It is a crucial assumption underlying formulas (B.11) and (B.12) that $u$ is either a decreasing function (i.e., $u(1)>u(2)>\ldots>$ $u(n))$ : "the further away, the less urgent") or that for some $k, u(I)=$ $u(2)=\ldots=u(k)=0$ and $u(k+1)>u(k+2)>\ldots>u(n)$.

Note 2.2. It appears on the surface that (B.11) and (B.12) come from a simple- minded substitution of $E$ and $\bar{F}$ for $F$ in (B.4), but in fact the derivation of these formulas is based on the theory of "Choquet expectation" of a random variable with respect to a "monotone" measure of uncertainty. It is not obvious from (B.11) and (B.12), for example, that 


$$
E(U) \leq \bar{E}(U),
$$

although (B.13) is in fact true, as one would certainly hope, based on our terminology. The proof of (B.13) is based on equivalent, less intuitive formulas for $E(U)$ and $\bar{E}(U)$.

Note 2.3. Using the argument of Note 1.1 above, one can show that formulas (B.11) and (B.12) for $E(U)$ and $\bar{E}(U)$ can be used even when $E(n)<1$ or $\bar{F}(n)<1$.

Traditionalists often object that imprecise probabilistic analysis may not lead to a clearcut ranking. In the present case, for example, there may be events $e_{i}$ and $e_{j}$ such that the intervals $\left[\underline{E}\left(U_{i}\right), \bar{E}\left(U_{i}\right)\right]$ and $\left[\underline{E}\left(U_{j}\right), \bar{E}\left(U_{j}\right)\right]$ overlap. How should we prioritize action on $e_{i}$ and $e_{j}$ in such a case? An obvious possibility is to take a weighted average of the lower and upper expected action urgency of each event $e_{i}$,

$$
A_{i}:=\propto E\left(U_{i}\right)+(1-\propto) \bar{E}\left(U_{i}\right)
$$

where $0 \leq \alpha \leq 1$. Call $A_{i}$ the "action priority" associated with event $e_{i}$. The parameter $\alpha$ is an index of optimism. The larger $\alpha$ is, the more credence planners give to scenarios tending toward a long "lead time" for the event in question.

\section{IMPRECISE HAZARD FUNCTIONS}

Instead of directly assessing the lower and upper $c d f \mathrm{~s} E$ and $\bar{F}$ required in formulas (B.11) and (B.12), it might occur to one to try to get at $E$ and $\bar{F}$ indirectly, assessing instead lower and upper hazard functions $\underline{G}$ and $\bar{G}$, where for all $j \geq 1$, 


$$
G(j)=\underline{P}(Y \leq j \mid Y>j-1), \text { and }
$$

$$
\bar{G}(j)=\bar{P}(Y \leq j \mid Y>j-1) .
$$

This approach is problematic for several reasons. First, there are several competing ways to condition lower and upper probabilities, so (B.15) and (B.16) are ambiguous. Second, even when the ambiguity in these formulas is resolved by selecting a particular method of conditioning, $G$ and $\bar{G}$ will not uniquely determine $E$ and $\bar{F}$.

To illustrate the latter point, let us take the most common method of conditioning (socalled "Bayesian conditioning") $P$ and $\bar{P}$. Here we imagine a family $\rho$ of all probability measures $P$ "compatible with" our limited evidence and the corresponding family $\mathscr{L}$ of $c d f s$ compatible with the evidence. In terms of these families, for each $j=1, \ldots n$,

$$
E(j)=\min _{P \in \mathscr{P}}\{P(Y \leq j)\}=\min _{F \in \mathscr{L}}\{F(y)\},
$$

$$
\bar{F}(j)=\max _{P \in \mathcal{P}}\{P(Y \leq j)\}=\max _{F \in \mathscr{L}}\{F(y)\},
$$

(B. 19)

$$
\begin{aligned}
G(j) & =\min _{P \in P}\{P(Y \leq j \mid Y>j-1)\} \\
& =\min \left\{\frac{F(j)-F(j-1)}{1-F(j-1)}\right\}, \text { and } \\
F \in \mathscr{P} &
\end{aligned}
$$


(B. 20)

$$
\begin{aligned}
\bar{G}(j) & =\max _{P \in \mathcal{P}}\{P(Y \leq j \mid Y>j-1)\} \\
& =\max \left\{\frac{F(j)-F(j-1)}{1-F(j-1)}\right\} .
\end{aligned}
$$

Take (B.19) for example. One does not necessarily minimize $(F(j)-F(j-1)) /(1-F(j-1))$ by minimizing each of its parts. While it is true that

$$
\begin{aligned}
& G(1)=\min \left\{\frac{F(1)-F(0)}{1-F(0)}\right\} \\
& F \in \mathscr{L} \\
&= \\
& \min \{F(1)\} \\
&=E \in \mathscr{L} \\
&=E(1),
\end{aligned}
$$

for $j \geq 2$ it is in general the case that

$$
\underline{G}(j) \neq \frac{E(j)-E(j-1)}{1-\underline{E}(j-1)} .
$$

So we cannot recover $\underline{F}$ from $\underline{G}$. Similar remarks apply to $\bar{G}$ and $\bar{F}$. Thus in problems involving imprecise probabilities, it is preferable to assess $E$ and $\bar{F}$ directly in pursuing the analysis described in $\$ 2$ above. If such direct assessment is impossible, one can pursue the following "rough" approach. Given $\underline{G}$, as defined by (B.19) and as assessed by the planners, define $F^{\star}$ by

$$
\text { (i) } \underline{F}^{\star}(1)=\underline{G}(1) \text {, and }
$$

$$
\text { (ii) } E^{\star}(j)=E_{\text {for } j \geq 2}^{E^{\star}}(j-1)+G(j)\left[1-E^{\star}(j-1)\right]
$$

Similarly, given $\bar{G}$, as defined by (B.20) and as assessed by the planners, define $\overline{F^{\star}}$ by 
(i) $\overline{F^{\star}}(1)=\bar{G}(1)$, and

(ii) $\overline{F^{\star}}(j)=\overline{F^{\star}}(j-1)+\bar{G}(j)\left[1-\overline{F^{\star}}(j-1)\right]$ for $j \geq 2$.

One then calculates a "rough lower expected action urgency" $E^{\star}(U)$ and a "rough upper expected action urgency" $\overline{E^{\star}}(U)$ by the formula

$$
\underline{E^{\star}}(U)=u(1) \underline{E^{\star}}(1)+\sum_{j=2}^{n} u(j)\left(\underline{F^{\star}}(j)-\underline{F^{\star}}(j-1)\right), \text { and }
$$

$$
\overline{E^{\star}}(U)=u(1) \overline{F^{\star}}(1)+\sum_{j=2}^{n} u(j)\left(\overline{F^{\star}}(j)-\overline{F^{\star}}(j-1)\right) .
$$

As in $\S 2$, one prioritizes action on a given event $e_{i}$ according to the magnitude of a weighted average

$$
A_{i}^{\star}:=\alpha \underline{E^{\star}}\left(U_{i}\right)+(1-\alpha) \overline{E^{\star}}\left(U_{i}\right)
$$

the "rough action priority associated with $e_{i}$.

Under certain regularity conditions on $P$ and $\bar{P}$, one can prove that

$$
E^{\star}(j) \leq E(j) \leq \bar{F}(j)+\overline{F^{\star}}(j),
$$

where $\underline{E}$ and $\bar{F}$ are the actual, but unknown lower and upper $c d f s$ and hence that

$$
E^{\star}(U) \leq E(U) \leq \bar{E}(U) \leq \overline{E^{\star}}(U),
$$


where $\underline{E}$ and $\bar{E}$ are the actual but unknown lower and upper expected action urgencies. Here the "rough" approach yields wider $c d f$ and expected action urgency intervals. It is worth noting that while (B.28) may be interpreted as asserting that $\underline{E}^{\star}$ is more conservative than $E$ and $\overline{F^{\star}}$ more conservative than $\bar{F}$, (B.29) does not admit of a similar interpretation. Conservatism here always resides in larger expected urgencies so $E^{\star}$ is less conservative than $E$ while $\overline{E^{\star}}$ is more conservative than $\bar{E}$. In view of this fact, it may be advisable to make $\alpha$ in (B.27) smaller than one would in (B.14). 


\section{INTERNAL DISTRIBUTION}

1. J. B. Cannon

2. G. E. Courville

3. T. R. Curlee

4. S. G. Hildebrand

5. C. I. Moser

6. R. M. Reed

7. M. Schweitzer
8. R. B. Shelton

9. B. E. Tonn

10. Central Research Library

11. Document Reference Section

12. Laboratory Records

13. Laboratory Records - RC

14. ORNL Patent Office

\section{EXTERNAL DISTRIBUTION}

15. Dr. Lilia A. Abron, President, PEER Consultants, P.C., 1460 Gulf Blvd., $11^{\text {th }}$ Floor, Clearwater, FL 34630.

16. Dr. Thomas E. Drabek, Professor, Department of Sociology, University of Denver, Denver, Co 80208-0209.

17. Mr. P. Richard Rittelmann, FAIA, Executive Vice President, Burt Hill Kosar Rittelmann Associates, 400 Morgan Center, Butler, PA 16001-5977.

18. Dr. Susan F. Tierney, The Economic Resource Group, Inc., One Mifflin Place, Cambridge, MA 02138 .

19. Dr. C. Michael Walton, Department of Civil Engineering, College of Engineering, The University of Texas at Austin, Cockrell Hall, Suite 4.2, Austin, TX 78712.

20. Office of Scientific and Technical Information, U.S. Department of Energy, P.O. Box 62, Oak Ridge, Tennessee 37831 